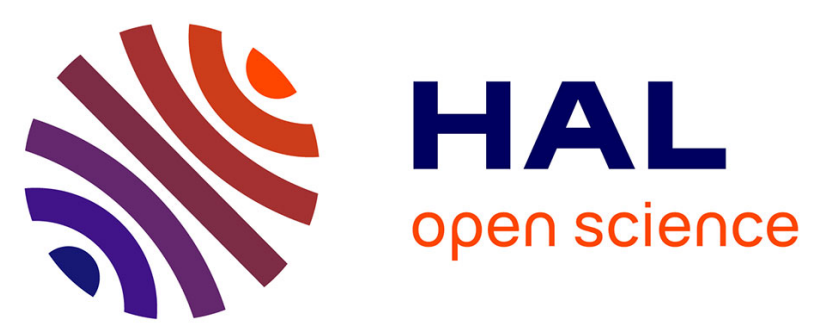

\title{
Circadian modulation of proteasome activity and accumulation of oxidized protein in human embryonic kidney HEK 293 cells and primary dermal fibroblasts
} Audrey Desvergne, Nicolas Ugarte, Sabrina Radjei, Monique Gareil, Isabelle Petropoulos, Bertrand Friguet

\section{To cite this version:}

Audrey Desvergne, Nicolas Ugarte, Sabrina Radjei, Monique Gareil, Isabelle Petropoulos, et al.. Circadian modulation of proteasome activity and accumulation of oxidized protein in human embryonic kidney HEK 293 cells and primary dermal fibroblasts. Free Radical Biology and Medicine, 2016, 94, pp.195-207. 10.1016/j.freeradbiomed.2016.02.037 . hal-01285511

\section{HAL Id: hal-01285511 \\ https://hal.sorbonne-universite.fr/hal-01285511}

Submitted on 9 Mar 2016

HAL is a multi-disciplinary open access archive for the deposit and dissemination of scientific research documents, whether they are published or not. The documents may come from teaching and research institutions in France or abroad, or from public or private research centers.
L'archive ouverte pluridisciplinaire HAL, est destinée au dépôt et à la diffusion de documents scientifiques de niveau recherche, publiés ou non, émanant des établissements d'enseignement et de recherche français ou étrangers, des laboratoires publics ou privés. 


\section{Circadian modulation of proteasome activity and accumulation of oxidized protein in human embryonic kidney HEK 293 cells and primary dermal fibroblasts}

Audrey Desvergne ${ }^{1,2,3}$, Nicolas Ugarte ${ }^{1,2,3}$, Sabrina Radjei ${ }^{1,2,3,4}$, Monique Gareil ${ }^{1,2,3}$, Isabelle Petropoulos ${ }^{1,2,3}$ and Bertrand Friguet ${ }^{1,2,3 *}$

${ }^{1}$ Sorbonne Universités, UPMC Univ Paris 06, UMR 8256, Biological adaptation and ageingIBPS, F-75005 Paris, France,

${ }^{2}$ CNRS UMR-8256, F-75005 Paris, France,

${ }^{3}$ INSERM U1164, F-75005 Paris, France,

${ }^{4}$ LVMH Research, St. Jean de Braye, France.

* Corresponding author. Tel: + 331442737 02; Fax: + 331442751 40, E-mail: bertrand.friguet@upmc.fr

\section{Abstract:}

The circadian system orchestrates the timing of physiological processes of an organism living in daily environmental changes. Disruption of circadian rhythmicity has been shown to result in increased oxidative stress and accelerated aging. The circadian regulation of antioxidant defenses suggests that other redox homeostasis elements such as oxidized protein degradation by the proteasome, could also be modulated by the circadian clock. Hence, we have investigated whether proteasome activities and oxidized protein levels would exhibit circadian rhythmicity in synchronized cultured mammalian cells and addressed the mechanisms underlying this process. Using synchronized human embryonic kidney HEK 293 cells and primary dermal fibroblasts, we have shown that the levels of carbonylated protein and proteasome activity vary rhythmically following a 24 hours period. Such a modulation of proteasome activity is explained, at least in part, by the circadian expression of both Nuclear factor (erythroid-derived 2)-like 2 (Nrf2) and the proteasome activator PA28 $\alpha \beta$. HEK 293 cells showed an increased susceptibility to oxidative stress coincident with the circadian- 
dependent lower activity of the proteasome. Finally, in contrast to young fibroblasts, no circadian modulation of the proteasome activity and carbonylated protein levels was evidenced in senescent fibroblasts. This paper reports a novel role of the circadian system for regulating proteasome function. In addition, the observation that proteasome activity is modulated by the circadian clock opens new avenues for both the cancer and the aging fields, as exemplified by the rhythmic resistance of immortalized cells to oxidative stress and loss of rhythmicity of proteasome activity in senescent fibroblasts.

\section{Key words:}

Proteasome, circadian rhythmicity, protein oxidation, HEK 293 cells, human dermal fibroblasts, oxidative stress, cellular aging, proteasome activator PA28 $\alpha \beta$, Nrf2.

\section{Introduction:}

The circadian clock generates rhythms with a periodicity of 24 hours of various biochemical and physiological processes such as sleep-wake cycles, body temperature, blood pressure, renal activity, and liver metabolism in mammals $[1,2]$ by regulating the expression of many genes, referred as to clock controlled genes $[3,4]$. The molecular mechanisms of the circadian clock involve a transcription/translation feedback loop composed by the activator heterodimer CLOCK/BMAL1 and the repressor heterodimer CRY/PER. In current models of the eukaryotic circadian oscillator, the transcription-translation feedback loop is considered as the prime mechanism sustaining intracellular rhythms. However, proteasome-mediated degradation of proteins, that also includes polyubiquitinated CRY and PER, is critically important for the core cellular circadian clock [5-7]. Furthermore, the peroxiredoxin redox state has been described as an additional non-transcriptional timekeeping mechanism conserved in both eukaryotes and prokaryotes [8]. This redox oscillation probably reflects an endogenous rhythm in the generation of reactive oxygen species (ROS) [9, 10] and the degradation or repair of hyperoxidized peroxiredoxin $[11,12]$. 
ROS can act as important signaling molecules for various cellular functions including circadian rhythms [13, 14] in many organisms such as Neuropora [15], Drosophila [16], zebrafish [17] and humans [10]. Interestingly in flies with a functional clock, it has been demonstrated daily fluctuations in both the levels of mitochondrial ROS and carbonylated protein, indicative of a circadian rhythm in the production of ROS and removal of protein oxidative damage [18]. Indeed, ROS can attack proteins in different ways and the most frequent irreversible end products are carbonylated proteins $[19,20]$ that accumulate with age [21]. This accumulation is related to a decrease of proteasome activity during aging [22-26]. Since protein carbonylation cannot be repaired and represents a threat to cell viability, carbonylated proteins are indeed eliminated mainly through degradation by the proteasome [27-29].

The proteasomal system, located in the nucleus and the cytosol, plays a crucial role in protein homeostasis and in the regulation of many cellular events since it degrades more than $70-80 \%$ of intracellular proteins [30]. The proteasome is able to bind different regulatory proteins. The ATP-dependent association of 19S regulator (PA700, "proteasome activator 700 $\mathrm{kDa}$ ") to the $\alpha$-rings of the core particle results in the formation of $26 \mathrm{~S}$ proteasome that degrades polyubiquitinated proteins. An other important regulator for both the proteasome and immunoproteasome, is the $11 \mathrm{~S}$ or PA28 $\alpha \beta$ regulator ("proteasome activator $28 \mathrm{kDa}$ "), the expression of which is induced by both IFN- $\gamma$ and Nrf2 (nuclear factor erythroid-derived 2like 2). Interestingly, the Nrf2 induced up-regulation of $20 \mathrm{~S}$ proteasome and PA28 $\alpha \beta$ has been recently implicated in the oxidative stress response through their efficient contribution to the intracellular removal of oxidized proteins [31].

The link between the circadian clock, ROS production, antioxidant defenses and removal of protein oxidative damage $[18,32]$ suggests that redox homeostasis elements such as oxidized protein degradation by the proteasome, could be modulated by the circadian system. Interestingly, microarray analysis revealed that several proteasome subunits are 
regulated by the circadian clock at the transcription level in mouse tissues $[33,34]$ and that Nrf2 levels show diurnal variation in mouse livers and Drosophila heads [35, 36].

Using two mammalian cellular models, we show in this paper, that both the immortalized HEK 293 cell line and primary human dermal fibroblasts (HDF) synchronized by a serum shock [37] exhibit a circadian rhythmicity of proteasome activity and accumulation of carbonylated proteins. The circadian regulation of proteasome activity can be explained, at least in part, by the circadian expression of PA28 $\alpha \beta$ and Nrf2 at the gene and protein levels which is associated with the rhythmic modulation of ROS production and oxidized glutathione content. When challenged with the oxidative agent tert-butyl hydroperoxide (t-BHP), synchronized HEK 293 cells showed differential sensitivity to oxidative stress depending on its timing. Finally, in contrast to young dermal fibroblasts, no circadian activation of the proteasome and rhythmic modulation of ROS levels could be evidenced in senescent fibroblasts.

\section{Materials and Methods}

\section{Materials}

Dulbecco's Modified Eagle Medium (4.5 $\mathrm{mg} \mathrm{mL}^{-1}$ glucose), penicillin, streptomycin, glutamine, trypsin solution for cell culture $(0.05 \%(\mathrm{w} / \mathrm{v}))$ were purchased from Sigma-Aldrich (Saint-Quentin Fallavier, France) and fetal bovine serum from Invitrogen Life technologies (Cergy Pontoise, France). Cell culture plastics were purchased from BD Falcon (Le Pont de Claix, France). Cell proliferation kit II (XTT) was obtained from Roche Diagnostics (Meylan, France). Western blot reagents and membranes were purchased from GE Healthcare (Saclay, France). The bicinchoninic acid (BCA) and Bradford protein assays were purchased from Thermo scientific (Villebon-sur-Yvette, France) and from Expedeon (San Diego, USA), respectively and chemicals for SDS/PAGE from Bio-Rad (Marnes La Coquette, France). 
$\mathrm{OxyBlot}^{\mathrm{TM}}$ protein oxidation detection kit was purchased from Millipore (Molsheim, France).

All other reagents were obtained from Sigma-Aldrich, unless specified.

\section{Cell culture and serum shock treatment}

HEK 293 cells were purchased from Sigma-Aldrich and primary HDF were kindly provided by Dr C. Nizard, LVMH-Research (Saint Jean de Braye, France). As previously described by Demirovic et al. (2015) for HDF culture studies, skin samples were collected from adult patients, undergoing abdominal plastic surgery performed by independent plastic surgeons and were considered as "waste", and thus were exempt from any further ethical approval [38]. All the waste tissues were completely de-identified prior to being handed over to the researchers. Both HEK 293 cells and HDF were cultivated in Dulbecco's Modified Eagle's Medium supplemented with $10 \%$ (v/v) fetal bovine serum, 2 mM L-Glutamine, 100 units $/ \mathrm{mL}$ penicillin and $100 \mu \mathrm{g} / \mathrm{mL}$ streptomycin at $37{ }^{\circ} \mathrm{C}$ and $5 \% \mathrm{CO}_{2}$ in a humidified incubator. After reaching a sub-confluence (of about $90 \%$ confluence), circadian synchronization of cells was performed by a serum shock treatment [37] that consists in a two hours exposure to a serum-rich medium (complete DMEM supplemented by $50 \%(\mathrm{v} / \mathrm{v})$ of fetal bovine serum). Then cells were replaced in a serum free culture medium. The beginning of the serum shock defined the time $0\left(\mathrm{t}_{\mathrm{oh}}\right)$. Then every $4 \mathrm{~h}$ and during $50 \mathrm{~h}$, cells were collected and RNA or protein extractions were performed.

The senescent HDF were obtained at late passages (passages between 43 and 46) and the replicative senescence of HDF was assessed by monitoring SA- $\beta$-galactosidase activity and $\mathrm{p} 16$ expression $[39,40]$.

\section{RNA extraction, reverse transcription and real time qPCR}

Total RNA from cultured cells was extracted using a NucleoSpin® RNA II kit (Macherey Nagel, Hoerdt, France). $2 \mu \mathrm{g}$ of total RNA was used to perform reverse 
transcription using a SuperScript ${ }^{\circledR}$ III First-Strand Synthesis System (Invitrogen Life Technologies) with random hexamers. Real time qPCR analysis was performed with a LightCycler ® 480 Real-Time PCR System (Roche Diagnostics), using a SYBR Green I dye for product detection. The sequences of the primers used to amplify cDNA are listed in Table 1 and were designed with the Life Invitrogen software (Custom Primers-OligoPerfect ${ }^{\mathrm{TM}}$ Designer). The cycling program was set up as followed: 5 min at $95{ }^{\circ} \mathrm{C}$ and 43 cycles at $95{ }^{\circ} \mathrm{C}$ for $15 \mathrm{sec}, 60{ }^{\circ} \mathrm{C}$ for $15 \mathrm{sec}$ and $72{ }^{\circ} \mathrm{C}$ for $15 \mathrm{sec}$. Gene expression was normalized with the reference gene gapdh which does not have circadian expression [41].

\section{Western Blot analyses}

For Western Blot analyses, proteins were extracted from cultured cells with a Cell Lytic solution (Sigma-Aldrich) following the manufacturer protocol and protein concentration was then measured by a BCA assay. $20 \mu \mathrm{g}$ of proteins were separated on SDS-PAGE (Criterion any KD precast gels, BioRad) and electro-transferred onto Hybond nitrocellulose membranes. Membranes were then blocked with the Odyssey blocking buffer (Li-Cor Biosciences, Lincoln, NE, USA) and incubated with Santa Cruz antibodies (Dallas, Texas, USA), p16 (sc-448) and Nrf2 (sc-365949), Enzo Life Sciences antibodies (Villeurbanne, France), either proteasome $\beta 1$ (BML-PW8140) and $\beta 5$ (BML-PW8895) and immunoproteasome $\beta 1 \mathrm{i}$ (BML-PW8205), $\beta 2 \mathrm{i}$ (BML-PW8150-0100) and $\beta 5 \mathrm{i}$ (PW8200) catalytic subunits and proteasome regulators PA28 $\alpha \beta$ (BML-PW185-0100, PW8240) at dilutions of $1 / 500$ for Nrf2, $1 / 1000$ for $p 16, \beta 1, \beta 2, \beta 5$, PA28 $\alpha \beta$ and $\beta 2 \mathrm{i}, 1 / 2000$ for $\beta 1 \mathrm{i}$ and $1 / 5000$ for $\beta 5 i$. Then, membranes were washed with PBS and incubated with species infraredconjugated secondary antibodies (Li-Cor Biosciences) at a dilution of 1/15000 and scanned with the Odyssey infrared imaging system (Li-Cor Biosciences). Signal intensities were quantified with the ImageJ software. 


\section{Protein carbonyl immunodetection after SDS-PAGE}

Immunoblot experiments for carbonyl detection were performed using the OxyBlot Protein Oxidation Detection Kit according to the manufacturer's instructions. Proteins were extracted from cultured cells with a Cell Lytic solution supplemented with 0.1 M DTT and protein concentration was then measured by a Bradford assay. Carbonyl groups of $10 \mu \mathrm{g}$ of proteins were derivatized to 2,4-dinitrophenylhydrazone by reaction with 2,4dinitrophenylhydrazine. The derivatized protein samples were separated on SDS-PAGE and electro-transferred onto Hybond nitrocellulose membranes. After Fast Green total proteins coloration (Sigma-Aldrich) and detection with the Odyssey infrared imaging system, the membranes were washed with a washing buffer (PBS 1X, tween $0.1 \% \mathrm{v} / \mathrm{v}$ ). Then, they were successively incubated with rabbit anti-dinitrophenol antibodies (Sigma-Aldrich, dilution of 1/5000) and processed following the same procedure as for the western blot analysis.

\section{Cell-Based Proteasome-Glo $\beta 1$ and $\beta 5$ Assay}

The proteasome chymotrypsin-like (ChT-L) and post-acid or caspase-like (PA) activities of cells were determined using a chemiluminescent assay (Proteasome Glo cellbased assay, Promega, Madison, U.S.A). The cells were dispensed into white opaque 384well microtiter plates (2500 cells/well, $25 \mu \mathrm{L}$ of culture medium per well). After one night of equilibration the cells were synchronized as described above. Then, every $4 \mathrm{~h}, 25 \mu \mathrm{L}$ of assay buffer containing a recombinant firefly luciferase and the luminogenic proteasome substrates Suc-LLVY-Glo (ChT-L activity) or Z-nLPnLD-Glo (PA activity) were added. After incubation at room temperature for $10 \mathrm{~min}$, chemiluminescence expressed as RLU (relative light unit) was measured on a Fluostar Optima plate reader (BMG Labtech, Champigny sur 
Marne, France) with a measuring time of 12 sec for each time. The proteasome activity was expressed as RLU/10 4 cells/min.

\section{Cell-Based GSH/GSSG-Glo Assay}

The measurements of total glutathione and oxidized glutathione were performed using a chemiluminescent assay (GSH/GSSG-Glo cell-based assay, Promega, Madison, U.S.A). The cells were dispensed into white opaque 384-well microtiter plates (2500 cells/well, $25 \mu \mathrm{L}$ of culture medium without red phenol per well). After one night of equilibration the cells were synchronized as described above. Every $4 \mathrm{~h}, 12.5 \mu \mathrm{L} /$ well of total glutathione lysis reagent or oxidized glutathione lysis reagent was added. After $5 \mathrm{~min}, 12.5 \mu \mathrm{L} /$ well of luciferin generation reagent was added to all wells and was incubated during $30 \mathrm{~min}$ at room temperature. Then, $50 \mu \mathrm{L} /$ well of luciferin detection reagent was put. After a further incubation at room temperature for $15 \mathrm{~min}$, chemiluminescence expressed as RLU (relative light unit) was measured on a BMG Labtech Fluostar Optima plate reader with an integration time of $1 \mathrm{sec}$ per well. The level of total glutathione and oxidized glutathione was expressed as RLU/10 4 cells.

\section{Total ROS detection by flow cytometry}

Cells were maintained with standard culture conditions as described above. The day before the experiment, 1 million of cells were seeded onto 6 well plates. After the synchronization treatment, the cells were incubated every $4 \mathrm{~h}$ during $15 \mathrm{~min}$ in the dark at 37 ${ }^{\circ} \mathrm{C}$ with the ROS probe 2,7- dichlorofluorescein diacetate (DCFDA, Sigma-Aldrich) dissolved in DMSO and used at a $10 \mu \mathrm{M}$ final concentration. After incubation with the dye, the cells were washed with PBS and fixed with $10 \%$ of cold methanol. The flow cytometric analysis of fluorescent cells was performed using MACSQuant Analyzer 10 (Miltenyi Biotec, Paris, France). DCFDA signal was detected using a $490 \mathrm{~nm}$ bandpass filter behind a $525 \mathrm{~nm}$ long- 
pass with a laser power of $25 \mathrm{~mW}$. The analyses were performed with the MACSQuantify software program. The level of ROS was expressed as FU/10 ${ }^{4}$ cells.

\section{Mathematical modeling and statistical analyses}

Results are presented as mean (or parameter value) of $n$ measurements of separate cultures from different stocks of the same clonal population \pm SEM. Data were treated as independent plots. All the fittings were performed by non-linear least squares regression, with the help of the mathematical software Origin 9.1 (OriginLab, RITME informatique, Paris, France). The raw data for each curves were fitted to a sinus-derived damped wave function added to a linear drift term:

$$
\mathrm{y}=\mathrm{y}_{0}+\mathrm{Ae}^{-\mathrm{x} / \mathrm{c}} \sin (\pi((\mathrm{t}-\varphi) / \tau)) \quad \text { with } \mathrm{A}>0, \tau>0, \mathrm{t}>0
$$

Where $\mathrm{y}_{0}$ represent the value before the serum shock, $\mathrm{A}$ is the amplitude, $\mathrm{c}$ is a constant decay, $t$ is time (h), $\tau$ is the endogenous period (h) and $\varphi$ is the phase (h).

The damping factor $\mathrm{e}^{-\mathrm{x} / \mathrm{c}}$ was applied to sinus-derived wave function to represent cell desynchronization over time. We removed the first two data points at $t_{0 h}$ and $t_{2 h}$ from the parameter estimation procedure as purely circadian variations may be perturbed by the serum shock during the first hours.

The pearson $\chi^{2}$ test and more particularly the chi-square which is also known as coefficient of determination and the adjusted r-square value that accounts for the degrees of freedom, were the statistical values used to determine the goodness of the fit.

Furthermore, the results were considered acceptable only if the variance (determined by ANOVA) between the raw data was not important $(\mathrm{p} \leq 0.01)$. Statistical differences according to circadian time were tested with multiple-way ANOVA including the Tukey and Fisher tests. Circadian parameters $(\mathrm{A}, \tau$ and $\varphi)$ were estimated simultaneously using the Origin 9.1 software. 


\section{Results}

\section{Circadian rhythmicity of proteasome peptidase activities and protein oxidative damage}

To investigate intracellular protein redox homeostasis and its regulation by the circadian clock in human cells, cultivated HEK 293 cells and primary HDF were synchronized by a serum shock [37] and samples were collected at regular intervals during two days for subsequent analyses. First, expression levels of circadian clock genes were assessed to confirm that both cellular models have been synchronized by the serum treatment. Circadian oscillations at the transcript levels were observed for bmal1 and per2 genes. As previously described [37] per2 expression was first induced after the serum shock, then the transcript level goes down and increases at $\mathrm{t}_{10 \mathrm{~h}-12 \mathrm{~h}}$ after the serum treatment to reach a peak of expression at $\mathrm{t}_{22 \mathrm{~h}-26 \mathrm{~h}}$ (Fig. 1A \& $\left.\mathrm{A}^{\prime}\right)$. These clock genes oscillate with a circadian period between $21.3 \pm 1.1 \mathrm{~h}($ bmall $)$ and $24.5 \pm 0.9 \mathrm{~h}$ (per 2$)$ for HEK 293 cells and between $24.6 \pm$ $0.8 \mathrm{~h}($ bmall $)$ and $26.9 \pm 0.8 \mathrm{~h}$ (per2) for HDF. As expected, the circadian pattern of the activator bmall is in antiphase with the one of per2 (Fig. 1A \& A'). Thus, the serum shock treatment successfully synchronized HEK 293 cells and HDF in vitro.

Proteins carrying irreversible oxidative damage such as carbonyls have been reported to be mainly degraded by the proteasome. Therefore, to find out if the proteasome and protein carbonyl formation follow circadian oscillations, proteasome peptidase activities were monitored within cells (Fig. 1B \& B') and protein carbonyl levels were analysed in cellular extracts (Fig. 1C \& C') in serum shock synchronized cells. Both ChT-L and PA proteasome activities display similar circadian patterns (Fig 1B \& B'). The serum shock treatment generates a peak of activity followed by a decrease until $\mathrm{t}_{18 \mathrm{~h}-20 \mathrm{~h}}$, then both activities increase again to reach a peak at $\mathrm{t}_{30 \mathrm{~h}-34 \mathrm{~h}}$, in the two cellular models, following a periodicity of $24.3 \pm$ 
$0.3 \mathrm{~h}(\mathrm{ChT}-\mathrm{L})$ and $24.2 \pm 0.4 \mathrm{~h}(\mathrm{PA})$ for HEK 293 cells and $23.1 \pm 0.6 \mathrm{~h}(\mathrm{ChT}-\mathrm{L})$ and $22.6 \pm$ $0.7 \mathrm{~h}(\mathrm{PA})$ for $\mathrm{HDF}$ (Fig. 1B \& B').

To determine the levels of protein carbonyls, synchronized cells were harvested every $4 \mathrm{~h}$ for $50 \mathrm{~h}$ and proteins were then extracted and their carbonyls derivatized with DNPH to be monitored by immunochemistry as described in Material and Methods. Protein carbonyls content was found to be modulated rhythmically with a period of $21.3 \pm 0.5 \mathrm{~h}$ for HEK 293 cells and a period of $22.9 \pm 0.7 \mathrm{~h}$ for HDF. The serum shock treatment results in two maximum peaks, one around $\mathrm{t}_{22 \mathrm{~h}}$ and one around $\mathrm{t}_{46 \mathrm{~h}}$ (Fig. $1 \mathrm{C} \& \mathrm{C}^{\prime}$ ). Interestingly, proteasome activity tracks the circadian oscillations of carbonyls formation since its peptidase activities and protein carbonyl levels oscillate in anti-phase.

\section{Circadian expression of constitutive proteasome and immunoproteasome catalytic subunits and PA28 $\alpha \beta$ at the mRNA and protein levels}

To further investigate how the circadian clock regulates proteasome activities, the mRNA and protein levels of 20 S proteasome catalytic $\beta$ subunits were analyzed (Fig. 1D \& $\mathrm{D}^{\prime}$ and $1 \mathrm{E} \& \mathrm{E}$ '). Gene expression analyses show that transcript levels of $\beta 1$ and $\beta 5$ catalytic subunits exhibit circadian oscillations with a period of $22.1 \pm 1.3 \mathrm{~h}(\beta 1)$ and $21.4 \pm 1.1 \mathrm{~h}(\beta 5)$ for HEK 293 cells and with a period of $23.4 \pm 1.2 \mathrm{~h}(\beta 1)$ and $22.4 \pm 1.1 \mathrm{~h}(\beta 5)$ in HDF. Nevertheless, protein expression of the $20 \mathrm{~S}$ proteasome catalytic $\beta$ subunits did not show circadian oscillations, suggesting that the cyclic proteasome activity may result from its activation rather than de novo synthesis of its subunits. Indeed, it has been described that both the 20S immunoproteasome and the proteasome activator PA28 $\alpha \beta(11 S)$ are implicated in the degradation of oxidized proteins [31]. The mRNA (Fig. 2A \& A') and protein (Fig. 2B \& B') expression analyses of $20 \mathrm{~S}$ immunoproteasome $\beta 1 \mathrm{i}$ and $\beta 5 \mathrm{i}$ catalytic subunits revealed that only $\beta 5$ i exhibits circadian oscillations at both mRNA and protein levels in the two cellular models with a periodicity around $22.6 \pm 1.3 \mathrm{~h}$ (mRNA) and $22.2 \pm 1.5$ (protein) for HEK 293 
cells (Fig. 2A and 2B) and 25.5 $\pm 0.9 \mathrm{~h}$ (mRNA) 23.2 $\pm 0.5 \mathrm{~h}$ (protein) for HDF (Fig. 2A' and 2B').

Besides 20S proteasome catalytic $\beta 1$ and $\beta 5$ and immunoproteasome catalytic $\beta 5 \mathrm{i}$ subunits, gene expression analyses also revealed that PA28 $\alpha \beta$ is under the clock control. Both PA28 $\alpha$ and PA28 $\beta$ components are rhythmically produced at the mRNA and protein levels in the two cellular models. In HEK 293 cells, $P A 28 \alpha \beta$ shows, an oscillating period of $21.1 \pm 1.1$ h for $P A 28 \alpha$ and $21.7 \pm 1.4$ h for $P A 28 \beta$ at the transcript level (Fig. 2C). The PA28 $\alpha$ and $\beta$ proteins also display circadian rhythmicity with periods of $25.2 \pm 0.9 \mathrm{~h}$ and $20.8 \pm 1.3 \mathrm{~h}$ respectively with peaks of expression around $t_{25 h}$ and $t_{50 h}$ (Fig. 2D). In HDF, the circadian period of $P A 28 \alpha$ is $26.2 \pm 0.8 \mathrm{~h}$ and $27.2 \pm 0.5 \mathrm{~h}$ for $P A 28 \beta$ at the transcript level (Fig. 2C'). The PA28 $\alpha$ and $\beta$ proteins oscillate with maximum peaks around $t_{27 \mathrm{~h}}$ and $\mathrm{t}_{51 \mathrm{~h}}$ and display circadian periods of $25.6 \pm 1.2 \mathrm{~h}$ and $23.4 \pm 0.7 \mathrm{~h}$ respectively (Fig.2D'). Interestingly, in both cellular models the oscillation of PA28 $\alpha \beta$ protein levels precedes the one of proteasome activities.

\section{Circadian rhythmicity of Nrf2 gene and protein expression, ROS production and oxidized glutathione content}

To further elucidate the circadian modulation of proteasome peptidase activities and oxidized protein content, we have analyzed Nrf2 expression and monitored ROS production and the intracellular redox status by measuring oxidized glutathione. Indeed, Pickering et al. (2012) have shown that adaptation to oxidative stress includes Nrf2-dependent increase in cellular capacity to degrade oxidized proteins that are attributable to increased expression of $20 \mathrm{~S}$ proteasome and immunoproteasome subunits and of PA28 $\alpha \beta$ [31]. Moreover, transcript levels of $N r f 2$, as well as several of its target genes, have been recently reported to show diurnal variation in mouse livers and Drosophila heads $[35,36]$. To investigate whether Nrf2 expression is subjected to circadian modulation that would explain, at least in part, the 
circadian up-regulation of $\mathrm{PA} 28 \alpha \beta$ and proteasome catalytic $\beta$ subunits, Nrf2 mRNA and protein levels were determined in synchronized HEK 293 cells and HDF. As shown in Fig. 3A \& A' and 3B \& B', both Nrf2 gene and protein expression followed circadian oscillations with a period of $24.4 \pm 0.8 \mathrm{~h}$ and $27.6 \pm 1.9 \mathrm{~h}$ respectively in HEK 293 cells (Fig. 3A \& B) and of $20.7 \pm 0.9 \mathrm{~h}$ and $23.1 \pm 1.2 \mathrm{~h}$ in HDF (Fig. 3A' \& B'). Interestingly, the circadian protein pattern of $\mathrm{Nrf} 2$ precedes the pattern of $\beta 1, \beta 2, \beta 5, \beta 5 \mathrm{i}$ and $P A 28 \alpha \beta$ mRNA levels. Since Nrf2 is one of the main sensor of oxidative stress, we measured the ROS level using the fluorescent probe DCFDA by flow cytometry as described in Materials and Methods. As shown in Fig. 3C \& C', ROS are produced rhythmically with a period of $22.6 \pm 0.8 \mathrm{~h}$ in HEK 293 cells and of $22.1 \pm 0.7 \mathrm{~h}$ in HDF. Interestingly, their oscillation pattern slightly precedes, in HEK 293 cells, or matches, in HDF, the protein carbonyls pattern and is in anti-phase with proteasome activities. The intracellular redox status was also monitored by assessing an antioxidant defense system known to be controlled by the Nrf2 pathway, namely the glutathione system. The levels of oxidized glutathione was measured and exhibited circadian fluctuations with a period of $24.6 \pm 0.4 \mathrm{~h}$ for HEK 293 cells and $22.1 \pm 2.5 \mathrm{~h}$ for HDF (Fig. 3D \& D').

\section{Differential sensitivity of synchronized HEK 293 cells to oxidative stress depending of its timing}

Since the proteasome, PA28 $\alpha \beta$ and Nrf2 are under circadian control, the sensitivity of synchronized HEK 293 cells to external oxidative stress applied at different times was tested. Synchronized HEK 293 cells were exposed during $1 \mathrm{~h}$ to $200 \mu \mathrm{M}$ of oxidative agent tert-butyl hydroperoxide (t-BHP) at $\mathrm{t}_{6 \mathrm{~h}}, \mathrm{t}_{18 \mathrm{~h}}, \mathrm{t}_{30 \mathrm{~h}}$ and $\mathrm{t}_{42 \mathrm{~h}}$. It appears that cells are significantly more resistant to oxidative stress at $t_{6 h}$ and $t_{30 h}$ as compared to $t_{18 h}$ and $t_{42 h}$ (Fig. 4). The former times correspond to the high range of proteasome peptidase activities and PA28 $\alpha \beta$ protein expression while the latter match the nadir of both parameters. Interestingly, the high survival 
rates also match the lower levels of oxidized glutathione. Hence, HEK 293 cells are more resistant to external oxidative stress when the proteasome peptidase activities are high, which also corresponds to the lower range of oxidized protein and glutathione (Fig. 1C) and endogenous ROS levels (Fig. 3C).

\section{Lack of circadian rhythmicity of proteasome peptidase activities, protein oxidative damage, ROS production and oxidized glutathione content in synchronized senescent HDF}

Cellular replicative senescence represents a model for studying cellular aging while senescent cells have also been implicated both in organismal aging and the occurrence of several age-related diseases $[1,42,43]$. Since senescent cells have been previously reported to exhibit increased oxidized protein levels, impaired proteasome function and expression of genes involved in the circadian clock [44, 45], HDF were grown until they reached senescence (passage between 43 and 46), monitored by SA- $\beta$-galactosidase activity and p16, and then synchronized by a serum shock. Expression levels of bmall and per 2 genes were analyzed and a circadian oscillation at the transcript level was observed for these two genes. Thus, the serum shock treatment successfully synchronized HDF in culture with members of the positive and negative hands of the core loop, bmall and per2 oscillating with periods of about $32.9 \pm 4.7 \mathrm{~h}$ and $31.4 \pm 3.9 \mathrm{~h}$ respectively (Fig. 5A), which is significantly longer than the period between $24.6 \pm 0.8 \mathrm{~h}$ and $26.9 \pm 0.8 \mathrm{~h}$ observed in young fibroblasts. As expected, proteasome peptidase activities were significantly lower by 4.5 fold in senescent cells $(82.4 \pm$ 23.4 RLU/10 ${ }^{4}$ cells/min; $\left.\mathrm{n}=3\right)$ as compared to young ones $\left(371.6 \pm 25.4 \mathrm{RLU} / 10^{4}\right.$ cells/min; n=3) while oxidized protein content was higher by about 2 fold. Their levels of ROS and GSSG were also found higher by about $3(10680 \pm 1044$ vs $3604 \pm 585$ FU/10 4 cells $)$ and 6 $\left(118 \times 10^{4} \pm 17 \times 10^{4}\right.$ vs $20 \times 10^{4} \pm 5 \times 10^{4}$ RLU/10 4 cells $)$ fold respectively in senescent cells as compared to young fibroblasts. In contrast to the synchronized young fibroblasts, proteasome 
activities (Fig. 5B) and protein carbonyl levels (Fig. 5C) did not exhibit circadian rhythmicity. Concerning the Nrf2 protein (Fig. 5D) and ROS levels (Fig. 5E), their rhythmicity are also completely lost. However, oxidized glutathione levels showed rhythmicity with a period of 48 $\mathrm{h}$ (Fig. 5F), which is longer than those of the clock genes in senescent cells (Fig. 5A) and about twice as much as the period observed for the young cells (Fig. 3D').

\section{Discussion}

The adaptation of organisms at different temporal niches is governed by the circadian clock. The daily variation of some stressors on ancient earth, especially oxidative atmosphere and strong solar radiation, can generate damages and promote various pathologies, forcing the circadian system to evolve as a protective system. Many studies describe ROS as one of the main inducers of biological disorders. Indeed, if the production and the elimination of ROS are not properly managed, the cells can undergo oxidative stress due to an imbalanced cellular redox state, leading to genomic and protein deterioration and ultimately to cell death. Protein carbonylation is the most widely used biomarker for oxidative damage to proteins, and reflects cellular damage induced by multiple forms of ROS. Carbonylated proteins cannot be repaired $[25,46]$ and are eliminated by the proteasome which represents the main proteolytic system implicated in many cellular pathways including oxidized protein degradation in the nucleus and the cytosol $[26,28,29]$. Age-associated impairment of proteasomal function has been reported to contribute to the accumulation of oxidized protein with age [24-26, 47]. ROS can also serve as second messengers to control physiological and pathological processes [48]. Thus, redox homeostasis appears to be critical for cellular function. A direct link between redox homeostasis and the circadian clock has been recently established since oscillations of the redox state of peroxiredoxin have been described as an additional timekeeping mechanism $[8,10,49]$. Interestingly, hyperoxidized peroxiredoxins have also been shown to be degraded by the proteasome, hence contributing to the peroxiredoxin redox state-dependent 
timekeeping mechanism. Moreover, circadian rhythmicity of anti-oxidative defenses and its aged-associated impairment has also been reported $[32,45]$ suggesting that other important elements of redox homeostasis such as oxidized protein degradation by the proteasome could be modulated by the circadian clock.

In this study, HEK 293 cells, as well as HDF, that represent a more physiologically relevant cellular model [50], were synchronized by a serum shock [37]. As expected, both mammalian cellular models showed oscillations of the circadian clock genes bmall and per 2 (Fig. 1A \& A'). In both cellular models, the proteasome peptidase activities exhibited circadian rhythmicity (Fig. 1B \& B'). This finding may have important implications for the rhythmic regulation of the abundance of proteins that are degraded by the proteasome and might also explain previously reported discrepancies between transcriptome and proteome circadian rhythmicity $[51,52]$. Interestingly, oxidatively damaged protein content, monitored by measuring levels of protein carbonylation as a function of time (Fig. 1C \& $\mathrm{C}^{\prime}$ ), also showed a circadian modulation, which was in anti-phase with the one observed for proteasome peptidase activities (Fig. 1B \& B'). A direct circadian regulation of many antioxidant enzymes with an E-Box present in their promoter sequence, as well as some proteasome subunits, has been previously evidenced at the transcript level by microarray analyses [53]. However, the rhythmic pattern that we observed for the catalytic $\beta$ subunits transcript levels (Fig. 1D \& D') was not found at the protein level (Fig. 1E \& E'), which indicates that the circadian modulation of proteasome peptidase activities may originate from other mechanisms than circadian de novo synthesis of proteasome subunits. Indeed, the constitutive $20 \mathrm{~S}$ proteasome has a long half-life of $133 \mathrm{~h}$ versus $27 \mathrm{~h}$ for the $20 \mathrm{~S}$ immunoproteasome [54]. Moreover, it has been shown that the 20S immunoproteasome and PA28 $\alpha \beta$ also play a key role in oxidized protein degradation [31]. Our results show that, in both synchronized HEK 293 cells and HDF, only one immunoproteasome catalytic subunit 
$\beta 5$ i (Fig. $2 \mathrm{~A} \& \mathrm{~A}^{\prime}$ and Fig. $2 \mathrm{~B} \& \mathrm{~B}^{\prime}$ ) but the two isoforms of the activator PA2 $2 \alpha \beta$ exhibited circadian oscillations both at the transcript and protein levels (Fig. 2C \& $\mathrm{C}^{\prime}$ and Fig. 2D \& D') that were matching those observed for proteasome peptidase activities (Fig. 1B \& B'). Furthermore, Pickering et al. (2012) have also reported a common regulation of constitutive proteasome and immunoproteasome catalytic subunits and their regulators. Indeed, due to the presence of an ARE (antioxidant response element) motif in the promoter sequence of $\beta 1, \beta 2$, $\beta 5, \beta 5 i$ and $P A 28 \alpha \beta$, they proposed that the Nrf2 pathway, which has been recently shown to be under circadian control [55], could be the master oxidative regulator of the proteasome. Interestingly, we did observe circadian oscillations only for $\beta 1, \beta 2, \beta 5, \beta 5 i$ and $P A 28 \alpha \beta$ mRNA levels and not for $\beta 1 i$ that has no ARE motif in its promoter sequence. Therefore, we have investigated the circadian regulation of Nrf2 pathway as an endogenous modulator of proteasome function in synchronized HEK 293 cells and HDF. As shown in Fig. 3, Nrf2 gene and protein expression, ROS production and oxidized glutathione were found to oscillate in a circadian manner. As summarized in Fig. 6, these findings suggest that the circadian controlled Nrf2 pathway stimulates oxidized protein degradation by the proteasome mainly through the circadian induction of de novo synthesis of the proteasome activator PA28 $\alpha \beta$. ROS oscillations matched the protein carbonylation ones and they were both in anti-phase with proteasome activities. Since the circadian transcription factor CLOCK/BMAL1 positively regulate $\mathrm{Nrf} 2$ transcription through temporal control of the E-box motif in the $N r f 2$ gene promoter, Nrf2 protein oscillates in a circadian manner and drive circadian transcription of the proteasome catalytic subunits and PA28 $\alpha \beta$ as well as a key set of antioxidant genes including those involved in glutathione metabolism as previously described $[36,55,56]$.

We next investigated whether the circadian modulation of protein redox homeostasis and degradation of oxidized protein by the proteasome would impact on cellular resistance to an external oxidative stress applied with equal strength at different times of the day. As shown in Fig. 4, HEK 293 cells exposed for $1 \mathrm{~h}$ to sub-lethal doses of t-BHP showed differential 
sensitivity to oxidative stress induced cell death depending on its timing. Interestingly, the highest sensitivity to oxidative stress was observed at $\mathrm{t}_{18 \mathrm{~h}}$ and $\mathrm{t}_{42 \mathrm{~h}}$, that both correspond to the lower proteasome peptidase activities and the higher levels of oxidized proteins and glutathione (Fig. 1C \& Fig. 3D). The importance of such circadian timing has been demonstrated in various biological areas. Indeed, previous studies strongly support the administration of drugs at certain times of day as a valuable method for improving anticancer treatment. Cancer chronotherapy can change by several fold the efficiency and tolerability of anticancer medications in experimental models and cancer patient [57]. Since the proteasome is a recognized target for anticancer treatment, it would be important to assess whether proteasome inhibition and hence anticancer treatment efficacy can be optimized depending on the timing of proteasome inhibitors addition. Indeed, several inhibitors are approved by the FDA as bortezomib and carfilzomib in the treatment of multiple myeloma [58, 59]. However, several studies have demonstrated that these inhibitors also induce resistance to cell death due to the activation of cell survival pathways $[60,61]$. In this context, administration of proteasome inhibitors at appropriate timing could increase their efficacy by reducing cancer cell resistance and decrease their toxicity-related side effects by using lower doses.

Finally, to analyze the effects of the circadian disturbance observed during aging and age-associated pathologies on redox homeostasis and degradation of oxidized proteins by the proteasome, we have measured proteasome activities, ROS, oxidized protein and glutathione levels in synchronized senescent HDF as a function of time. Indeed, age-related impairments of circadian rhythmicity have been reported in model organisms as well as in humans [62] while alterations of the circadian clock gene expression was observed in senescent smooth muscle cells in vitro and in vivo [44]. Although senescent HDF could be synchronized by the serum shock treatment (Fig. 5A), the bmall and per2 gene expression was oscillating with smaller amplitudes and longer periods observed with young HDF. In contrast with the synchronized young fibroblasts, neither proteasome activities, protein carbonyls, Nrf2, ROS, 
and oxidized glutathione levels showed circadian rhythmicity (Fig. 5B, C, D, E \& F). These findings are consistent with those reported by Stratford et al. (2006) who have shown a striking difference in the $\gamma$-interferon induced regulation of immunoproteasome levels in replicative senescence as compared with constitutive proteasome [63]. As already stated above, a hallmark of cellular aging is the accumulation of oxidatively damaged proteins that has been associated with both increased ROS production and alteration of protein maintenance systems such as the proteasome $[28,64]$. The link between the biological clock and protein redox homeostasis, including proteasome mediated oxidized protein degradation, could thus explain, at least in part, such changes observed during the aging process. Interestingly, the premature aging phenotype observed in bmall deficient mice has been linked to an increased of ROS levels compared to wild type mice that was suggested to originate as a consequence of the loss of the transcription activation by CLOCK/BMAL1 of the antioxidant enzymes [65]. In the light of our results, defects in protein redox homeostasis and alteration of proteasome function may also have contributed to this accelerated aging.

Taken together, our results support a critical link between the circadian clock, the redox homeostasis and the accumulation of oxidized protein during cellular aging.

\section{Acknowledgments}

The authors wish to acknowledge the support of FP6 EU Project Proteomage $\left(\mathrm{N}^{\circ}\right.$ 518230) and FP7 COST Action CM1001. In addition, they are very thankful to M. Moreau and C. Nizard from LVMH-Research for providing us the HDF, A. Munier, J.F. Gilles, and R. Schwartzmann from the Cell Imaging and Flow Cytometry Facility of the IBPS (Paris, France) for precious help in microscopy/cytometry/ image analysis and to A. Chaffotte from the Pasteur Institute (Paris, France) for his advice on mathematical modeling using Origin 9.1. 


\section{Abbreviations}

\section{ACCEPTED MANUSCRIPT}

ARE: antioxidant response element

BMAL1 or ARNTL: aryl hydrocarbon receptor nuclear translocator-like protein 1

CLOCK: circadian Locomotor Output Cycles Kaput

ChT-L: chymotrypsin-like

CRY: cryptochrome

DCFDA: 2,7- dichlorofluorescein diacetate

DNPH: dinitrophenylhydrazine

DTT: dithiothreitol

GSH: reduced glutathione

GSSG: oxidized glutathione

HDF: human dermal fibroblasts

HEK: human embryonic kidney cells

IFN- $\gamma$ : interferon $\gamma$

MHC: major Histocompatibility Complex

Nrf2: nuclear factor (erythroid-derived 2)-like 2

PA: post-acidic or caspase-like

PA28: proteasome activator 28

PBS: phosphate buffer saline

PER: period

ROS: reactive oxygen species

SEM: standard error of the mean

t-BHP: tert-butyl hydroperoxide

\section{References}

[1] Bollinger, T.; Schibler, U. Circadian rhythms - from genes to physiology and disease. 
Swiss Medical Weekly 144:w13984; 2014.

[2] Dibner, C.; Schibler, U.; Albrecht, U. The mammalian circadian timing system: organization and coordination of central and peripheral clocks. Annual Review of Physiology 72:517-549; 2010.

[3] Partch, C. L.; Green, C. B.; Takahashi, J. S. Molecular architecture of the mammalian circadian clock. Trends in Cell Biology 24:90-99; 2014.

[4] Robinson, I.; Reddy, A. B. Molecular mechanisms of the circadian clockwork in mammals. FEBS letters 588:2477-2483; 2014.

[5] Van Ooijen, G.; Dixon, L. E.; Troein, C.; Millar, A. J. Proteasome function is required for biological timing throughout the twenty-four hour cycle. Current Biology 21:869-875; 2011.

[6] Larrondo, L. F.; Olivares-Yanez, C.; Baker, C. L.; Loros, J. J.; Dunlap, J. C. Circadian rhythms. Decoupling circadian clock protein turnover from circadian period determination. Science 347: 1257277; 2015.

[7] Gallego, M.; Virshup, D. M. Post-translational modifications regulate the ticking of the circadian clock. Nature reviews. Molecular Cell Biology 8:139-148; 2007.

[8] Edgar, R. S.; Green, E. W.; Zhao, Y.; van Ooijen, G.; Olmedo, M.; Qin, X.; Xu, Y.; Pan, M.; Valekunja, U. K.; Feeney, K. A.; Maywood, E. S.; Hastings, M. H.; Baliga, N. S.; Merrow, M.; Millar, A. J.; Johnson, C. H.; Kyriacou, C. P.; O'Neill, J. S.; Reddy, A. B. Peroxiredoxins are conserved markers of circadian rhythms. Nature 485:459-464; 2012.

[9] O'Neill, J. S.; Feeney, K. A. Circadian redox and metabolic oscillations in mammalian systems. Antioxidant Redox Signaling 20:2966-2981; 2014.

[10] O'Neill, J. S.; Reddy, A. B. Circadian clocks in human red blood cells. Nature 469:498-503; 2011.

[11] Cho, C. S.; Yoon, H. J.; Kim, J. Y.; Woo, H. A.; Rhee, S. G. Circadian rhythm of hyperoxidized peroxiredoxin II is determined by hemoglobin autoxidation and the 20S proteasome in red blood cells. Proceedings of the National Academy of Sciences of the United States of America 111:12043-12048; 2014.

[12] Kil, I. S.; Ryu, K. W.; Lee, S. K.; Kim, J. Y.; Chu, S. Y.; Kim, J. H.; Park, S.; Rhee, S. G. Circadian Oscillation of Sulfiredoxin in the Mitochondria. Molecular Cell 59:651-663; 2015.

[13] Brown, D. I.; Griendling, K. K. Nox proteins in signal transduction. Free Radical Biology \& Medicine 47:1239-1253; 2009.

[14] Tamaru, T.; Hattori, M.; Ninomiya, Y.; Kawamura, G.; Vares, G.; Honda, K.; Mishra, D. P.; Wang, B.; Benjamin, I.; Sassone-Corsi, P.; Ozawa, T.; Takamatsu, K. ROS stress resets circadian clocks to coordinate pro-survival signals. PloS one 8:e82006; 2013.

[15] Gyongyosi, N.; Nagy, D.; Makara, K.; Ella, K.; Kaldi, K. Reactive oxygen species can modulate circadian phase and period in Neurospora crassa. Free Radical Biology \& Medicine 58:134-143; 2013.

[16] Grover, D.; Ford, D.; Brown, C.; Hoe, N.; Erdem, A.; Tavare, S.; Tower, J. Hydrogen peroxide stimulates activity and alters behavior in Drosophila melanogaster. PloS one 4:e7580; 2009.

[17] Hirayama, J.; Cho, S.; Sassone-Corsi, P. Circadian control by the reduction/oxidation pathway: catalase represses light-dependent clock gene expression in the zebrafish. Proceedings of the National Academy of Sciences of the United States of America 104:1574715752; 2007.

[18] Krishnan, N.; Davis, A. J.; Giebultowicz, J. M. Circadian regulation of response to oxidative stress in Drosophila melanogaster. Biochemical and Biophysical Research Communications 374:299-303; 2008.

[19] Shringarpure, R.; Grune, T.; Mehlhase, J.; Davies, K. J. Ubiquitin conjugation is not 
ACCEPTED MANUSCRIPT

required for the degradation of oxidized proteins by proteasome. The Journal of Biological Chemistry 278:311-318; 2003.

[20] Baraibar, M. A.; Friguet, B. Oxidative proteome modifications target specific cellular pathways during oxidative stress, cellular senescence and aging. Experimental Gerontology 48:620-625; 2013.

[21] Stadtman, E. R.; Levine, R. L. Free radical-mediated oxidation of free amino acids and amino acid residues in proteins. Amino acids 25:207-218; 2003.

[22] Conconi, M.; Szweda, L. I.; Levine, R. L.; Stadtman, E. R.; Friguet, B. Age-related decline of rat liver multicatalytic proteinase activity and protection from oxidative inactivation by heat-shock protein 90. Archives of Biochemistry and Biophysics 331:232-240; 1996.

[23] Petropoulos, I.; Conconi, M.; Wang, X.; Hoenel, B.; Bregegere, F.; Milner, Y.; Friguet, B. Increase of oxidatively modified protein is associated with a decrease of proteasome activity and content in aging epidermal cells. Journals of Gerontology Series aBiological Sciences and Medical Sciences 55:B220-B227; 2000.

[24] Baraibar, M. A.; Friguet, B. Changes of the proteasomal system during the aging process. Progress in Molecular Biology and Translational Science 109:249-275; 2012.

[25] Ferrington, D. A.; Husom, A. D.; Thompson, L. V. Altered proteasome structure, function, and oxidation in aged muscle. Faseb Journal 19:664-6; 2005.

[26] Kapphahn, R. J.; Bigelow, E. J.; Ferrington, D. A. Age-dependent inhibition of proteasome chymotrypsin-like activity in the retina. Experimental Eye Research 84:646-654; 2007.

[27] Balog, E. M.; Lockamy, E. L.; Thomas, D. D.; Ferrington, D. A. Site-specific methionine oxidation initiates calmodulin degradation by the $20 \mathrm{~S}$ proteasome. Biochemistry 48:3005-3016; 2009.

[28] Friguet, B. Oxidized protein degradation and repair in ageing and oxidative stress. FEBS letters 580:2910-2916; 2006.

[29] Chondrogianni, N.; Petropoulos, I.; Grimm, S.; Georgila, K.; Catalgol, B.; Friguet, B.; Grune, T.; Gonos, E. S. Protein damage, repair and proteolysis. Molecular Aspects of Medicine 35:1-71; 2014.

[30] Groll, L. B. a. M. 20S Proteasome and Its Inhibitors: Crystallographic Knowledge for Drug Development. Chemical Reviews. 107:687-717; 2007.

[31] Pickering, A. M.; Linder, R. A.; Zhang, H.; Forman, H. J.; Davies, K. J. Nrf2dependent induction of proteasome and $\mathrm{Pa} 28$ alphabeta regulator are required for adaptation to oxidative stress. The Journal of Biological Chemistry 287:10021-10031; 2012.

[32] Patel, S. A.; Velingkaar, N. S.; Kondratov, R. V. Transcriptional control of antioxidant defense by the circadian clock. Antioxidant Redox Signaling 20:2997-3006; 2014.

[33] Satchidananda Panda; Marina P. Antoch; Brooke H. Miller; Andrew I. Su; Andrew B. Schook; Marty Straume; Peter G. Schultz; Steve A. Kay; Joseph S. Takahashi; Hogenesch, J. B. Coordinated Transcription of Key Pathways in the Mouse by the Circadian Clock. Cell 109:307-320; 2002.

[34] Akhtar, R. A.; Reddy, A. B.; Maywood, E. S.; Clayton, J. D.; King, V. M.; Smith, A. G.; Gant, T. W.; Hastings, M. H.; Kyriacou, C. P. Circadian Cycling of the Mouse Liver Transcriptome, as Revealed by cDNA Microarray, Is Driven by the Suprachiasmatic Nucleus. Current Biology 12 540-550; 2002.

[35] Beaver, L. M.; Klichko, V. I.; Chow, E. S.; Kotwica-Rolinska, J.; Williamson, M.; Orr, W. C.; Radyuk, S. N.; Giebultowicz, J. M. Circadian regulation of glutathione levels and biosynthesis in Drosophila melanogaster. PloS one 7:e50454; 2012.

[36] Xu, Y. Q.; Zhang, D.; Jin, T.; Cai, D. J.; Wu, Q.; Lu, Y.; Liu, J.; Klaassen, C. D. 
ACCEPTED MANUSCRIPT

Diurnal variation of hepatic antioxidant gene expression in mice. PloS one 7:e44237; 2012.

[37] Balsalobre, A.; Damiola, F.; Schibler, U. A Serum Shock Induces Circadian Gene Expression in Mammalian Tissue Culture Cells. Cell 93:929-937; 1998.

[38] Demirovic, D.; Nizard, C.; Rattan, S. I. Basal level of autophagy is increased in aging human skin fibroblasts in vitro, but not in old skin. PloS one 10:e0126546; 2015.

[39] Campisi, J. Aging, cellular senescence, and cancer. Annual Review of Pphysiology 75:685-705; 2013.

[40] Munoz-Espin, D.; Serrano, M. Cellular senescence: from physiology to pathology. Nature reviews. Molecular Cell Biology 15:482-496; 2014.

[41] Vandesompele, J.; De Preter, K.; Pattyn, F.; Poppe, B.; Van Roy, N.; De Paepe, A.; Speleman, F. Accurate normalization of real-time quantitative RT-PCR data by geometric averaging of multiple internal control genes. Genome Biology 3:RESEARCH0034; 2002.

[42] Kelleher, F. C.; Rao, A.; Maguire, A. Circadian molecular clocks and cancer. Cancer letters 342:9-18; 2014.

[43] Arellanes-Licea, E.; Caldelas, I.; De Ita-Perez, D.; Diaz-Munoz, M. The circadian timing system: a recent addition in the physiological mechanisms underlying pathological and aging processes. Aging and Disease 5:406-418; 2014.

[44] Kunieda, T.; Minamino, T.; Katsuno, T.; Tateno, K.; Nishi, J.; Miyauchi, H.; Orimo, M.; Okada, S.; Komuro, I. Cellular senescence impairs circadian expression of clock genes in vitro and in vivo. Circulation Research 98:532-539; 2006.

[45] Khapre, R. V.; Kondratova, A. A.; Susova, O.; Kondratov, R. V. Circadian clock protein BMAL1 regulates cellular senescence in vivo. Cell cycle 10:4162-4169; 2011.

[46] Nystrom, T. Role of oxidative carbonylation in protein quality control and senescence. The EMBO Journal 24:1311-1317; 2005.

[47] Ethen, C. M.; Hussong, S. A.; Reilly, C.; Feng, X.; Olsen, T. W.; Ferrington, D. A. Transformation of the proteasome with age-related macular degeneration. FEBS letters 581:885-890; 2007.

[48] Thannickal, V. J.; Fanburg, B. L. Reactive oxygen species in cell signaling. American Journal of Physiology, Lung Cellular and Molecular Physiology 279:L1005-1028; 2000.

[49] O'Neill, J. S.; van Ooijen, G.; Dixon, L. E.; Troein, C.; Corellou, F.; Bouget, F. Y.; Reddy, A. B.; Millar, A. J. Circadian rhythms persist without transcription in a eukaryote. Nature 469:554-558; 2011.

[50] Sandu, C.; Dumas, M.; Malan, A.; Sambakhe, D.; Marteau, C.; Nizard, C.; Schnebert, S.; Perrier, E.; Challet, E.; Pevet, P.; Felder-Schmittbuhl, M. P. Human skin keratinocytes, melanocytes, and fibroblasts contain distinct circadian clock machineries. Cellular and Molecular Life Sciences 69:3329-3339; 2012.

[51] Yang, C.; Schmidt, M. Cutting through complexity: the proteolytic properties of alternate immunoproteasome complexes. Chemistry \& Biology 21:435-436; 2014.

[52] Luck, S.; Thurley, K.; Thaben, P. F.; Westermark, P. O. Rhythmic degradation explains and unifies circadian transcriptome and proteome data. Cell Reports 9:741-751; 2014.

[53] Yan, J.; Wang, H.; Liu, Y.; Shao, C. Analysis of gene regulatory networks in the mammalian circadian rhythm. PLoS Computational Biology 4:e1000193; 2008.

[54] Heink, S.; Ludwig, D.; Kloetzel, P. M.; Kruger, E. IFN-gamma-induced immune adaptation of the proteasome system is an accelerated and transient response. Proceedings of the National Academy of Sciences of the United States of America 102:9241-9246; 2005.

[55] Pekovic-Vaughan, V.; Gibbs, J.; Yoshitane, H.; Yang, N.; Pathiranage, D.; Guo, B. Q.; Sagami, A.; Taguchi, K.; Bechtold, D.; Loudon, A.; Yamamoto, M.; Chan, J.; van der Horst, G. T. J.; Fukada, Y.; Meng, Q. J. The circadian clock regulates rhythmic activation of the NRF2/glutathione-mediated antioxidant defense pathway to modulate pulmonary fibrosis. 
Genes \& Development 28:548-560; 2014.

\section{$\triangle$ CCEPTHED MANUSCRIPT}

[56] Lee, J.; Moulik, M.; Fang, Z.; Saha, P.; Zou, F.; Xu, Y.; Nelson, D. L.; Ma, K.; Moore, D. D.; Yechoor, V. K. Bmal1 and beta-cell clock are required for adaptation to circadian disruption, and their loss of function leads to oxidative stress-induced beta-cell failure in mice. Molecular and Cellular Biology 33:2327-2338; 2013.

[57] Levi, F.; Okyar, A.; Dulong, S.; Innominato, P. F.; Clairambault, J. Circadian timing in cancer treatments. Annual Review of Pharmacology and Toxicology 50:377-421; 2010.

[58] Richardson, P. G.; Mitsiades, C.; Hideshima, T.; Anderson, K. C. Bortezomib: proteasome inhibition as an effective anticancer therapy. Annual Review of Medecine 57:3347; 2006.

[59] McBride, A.; Klaus, J. O.; Stockerl-Goldstein, K. Carfilzomib: a second-generation proteasome inhibitor for the treatment of multiple myeloma. American Journal of HealthSystem Pharmacy 72:353-360; 2015.

[60] Barrera, L. N.; Rushworth, S. A.; Bowles, K. M.; MacEwan, D. J. Bortezomib induces heme oxygenase-1 expression in multiple myeloma. Cell Cycle 11:2248-2252; 2012.

[61] Niewerth, D.; Jansen, G.; Assaraf, Y. G.; Zweegman, S.; Kaspers, G. J.; Cloos, J. Molecular basis of resistance to proteasome inhibitors in hematological malignancies. Drug Resistance Updates 18:18-35; 2015.

[62] Kondratov, R. V. A role of the circadian system and circadian proteins in aging. Ageing Research Reviews 6:12-27; 2007.

[63] Stratford, F. L.; Chondrogianni, N.; Trougakos, I. P.; Gonos, E. S.; Rivett, A. J. Proteasome response to interferon-gamma is altered in senescent human fibroblasts. FEBS letters 580:3989-3994; 2006.

[64] Ugarte, N.; Petropoulos, I.; Friguet, B. Oxidized mitochondrial protein degradation and repair in aging and oxidative stress. Antioxidant Redox Signaling 13:539-549; 2010.

[65] Kondratov, R. V.; Kondratova, A. A.; Gorbacheva, V. Y.; Vykhovanets, O. V.; Antoch, M. P. Early aging and age-related pathologies in mice deficient in BMAL1, the core componentof the circadian clock. Genes \& Development 20:1868-1873; 2006.

\section{Table}

Table 1: Sequences of primers used for the Real-Time qPCR analyses.

\begin{tabular}{|c|c|c|}
\hline Gene & Forward primer & Reverse primer \\
\hline $\begin{array}{l}\text { Gapd } \\
h\end{array}$ & 5'TGCACCACCAACTGCTTAGC 3' & 5'GGCATGGACTGTGGTCATGAG 3' \\
\hline Per2 & $\begin{array}{l}\text { 5'GGTGCACAGCCCTCATTCTTTTC } \\
\text { A 3, }\end{array}$ & $\begin{array}{l}\text { 5'CCTCACTTTTCCCCAAGTGTCCA } \\
\text { A 3' }\end{array}$ \\
\hline Bmal & $\begin{array}{l}\text { 5'AGCCCATTGAACATCACGAGTAC } \\
\text { G 3' }\end{array}$ & $\begin{array}{l}\text { 5'AGTAGGCCACTGGAAGGAATGT } \\
\text { CT 3' }\end{array}$ \\
\hline$\beta 1$ & 5'CTGCGATTTTCGCCCTACGTTT 3' & $\begin{array}{l}\text { 5'AACCGCTGCATCCAATGACTGT } \\
3,\end{array}$ \\
\hline$\beta 2$ & $\begin{array}{l}\text { 5'GCCAGCGCTGTATTACATGGACT } \\
\text { A 3' }\end{array}$ & $\begin{array}{l}\text { 5'ACACTGAAGGTTGGCAGATTCAG } \\
\text { G 3' }\end{array}$ \\
\hline
\end{tabular}




\begin{tabular}{|l|l|l|}
\hline $\boldsymbol{\beta 5}$ & $\begin{array}{l}\text { 5'TGTTGGCTCGGCAATGTCGAAT } \\
\text { 3' }\end{array}$ & $\begin{array}{l}\text { 5'CTGAAATCCGGTTCCCTTCACTG } \\
\text { T 3' }\end{array}$ \\
\hline $\boldsymbol{\beta 1 i}$ & 5'CGTTGTGATGGGTTCTGATTC 3' & $\begin{array}{l}\text { 5'GACAGCTTGTCAAACACTCGGTT } \\
\text { 3' }\end{array}$ \\
\hline $\boldsymbol{\beta 2 i}$ & $\begin{array}{l}\text { 5'CCTTGCTTCAACAGGTGAGTTTG } \\
\text { C 3' }\end{array}$ & $\begin{array}{l}\text { 5'AGCCCATTGAACATCACGAGTAC } \\
\text { G 3' }\end{array}$ \\
\hline $\boldsymbol{\beta 5 i}$ & 5'GCCAAGGATTCTCGGGCC 3' & $\begin{array}{l}\text { 5'GCCAAGCAGGTAAGGGTTAATCT } \\
\text { C 3' }\end{array}$ \\
\hline $\boldsymbol{P A 2 8}$ & 5'TCCTTCTGCAGCGCTTGAA 3' & $\begin{array}{l}\text { 5'CTCAATCCGAGGTATCTGCAGC } \\
\text { 3' }\end{array}$ \\
\hline $\boldsymbol{P}$ & & $\begin{array}{l}\text { 5'TCAGCCTCCTGGAAAAGATTCTG } \\
\text { 3' }\end{array}$ \\
\hline $\boldsymbol{\beta}$ & 5'GTGCGCCTGAGCGGG 3' & 5'CAACAGGGAGGTTAATGATT 3' \\
\hline $\mathbf{N r f 2}$ & 5'TGCCCCTGGAAGTCAAACA3' \\
\hline
\end{tabular}

Primers for the reference gene gapdh were designed according to previously published sequences [49] while the remaining sequences were designed with the AmplifX software.

Figure legends

Figure 1: Proteasome peptidase activities and protein oxidative damage display circadian rhythmicity in synchronized HEK 293 cells and HDF

Sub-confluent HEK 293 cells and HDF were synchronized using a serum shock as described in Materials and Methods. Cells were harvested after a $2 \mathrm{~h}$ exposure to a medium containing $50 \%(\mathrm{v} / \mathrm{v})$ of serum and then every $4 \mathrm{~h}$ for $50 \mathrm{~h}$ in a serum free medium.

(A)(A') Total RNA was extracted and mRNA levels of clock circadian genes were determined by Real Time qPCR. The expression of both per2 (closed squares) and bmall (open squares) exhibited a circadian periodicity of $21.3 \pm 1.1 \mathrm{~h}$ and $24.5 \pm 0.9 \mathrm{~h}$ respectively in the HEK 293 cells (A) and $24.6 \pm 0.8 \mathrm{~h}$ and $26.9 \pm 0.8 \mathrm{~h}$ in HDF (A'), hence validating serum shock synchronized HEK 293 cells and HDF as circadian cellular models. As expected, the expression of per2 (closed circles) did not show circadian rhythmicity in non synchronized HEK 293 cells and HDF.

(B)(B') Intracellular proteasome peptidase activities were monitored using a Cell-Based Proteasome-Glo $\beta 5$ and $\beta 1$ Assay as described in Material and Methods. ChT-L (closed 
squares) and PA (open squares) activities were measured using the chemiluminescent substrates, Suc-LLVY-Glo and Z-nLPnLD-Glo, respectively. In the both cellular models the two proteasome peptidase activities exhibited a circadian rhythmicity $24.3 \pm 0.3 \mathrm{~h}$ and $24.2 \pm$ $0.4 \mathrm{~h}$ for HEK 293 cells $(\mathbf{B})$ and $23.1 \pm 0.6 \mathrm{~h}$ and $22.6 \pm 0.7 \mathrm{~h}$ for HDF (B').

$(\mathbf{C})\left(\mathbf{C}^{\prime}\right)$ Oxidized protein content (closed circles) was monitored using protein carbonyl Western Blot detection as described in Material and Methods. Quantification of protein carbonyl content was achieved using the ImageJ software. Protein carbonylation exhibited a circadian rhythmicity with periods of $21.3 \pm 0.5 \mathrm{~h}$ in HEK 293 cells $(\mathbf{C})$ and $22.9 \pm 0.7 \mathrm{~h}$ in $\operatorname{HDF}\left(\mathbf{C}^{\prime}\right)$

(D)(D') Total RNA was extracted and mRNA levels of 20S proteasome catalytic subunits $\beta 1$ (open squares) and $\beta 5$ (closed squares) were determined by Real Time qPCR. The transcript expression of proteasome catalytic subunits exhibited a circadian rhythmicity with a period of $22.1 \pm 1.3$ and $21.4 \pm 1.1 \mathrm{~h}$ respectively in HEK 293 cells $(\mathbf{D})$ and $23.4 \pm 1.2 \mathrm{~h}$ and $22.4 \pm 1.1$ h for the HDF (D').

$(\mathbf{E})(\mathbf{E}$ ') The expression of $20 \mathrm{~S}$ proteasome $\beta 1$ (open squares) and $\beta 5$ (closed squares) catalytic subunits was analyzed at the protein level in cellular extracts by western blotting as described in Material and Methods. Quantification of proteasome subunit content was achieved using the ImageJ software. In the both cellular models no circadian rhythmicity were detected at the protein level for the catalytic subunits.

Expression values of all genes were first normalized to the gapdh gene expression while expression values of all proteins were first normalized to the total protein load obtained upon Fast Green gel staining. A second normalization to the mean value of the time course experiment was performed for gene and protein expression levels, carbonylated protein content and proteasome activities.

Results are expressed as means $+/-\mathrm{SEM}, n=5$. All the curves and the periods were obtained using the Origin 9.1 software (OriginLab).

Figure 2: Proteasome catalytic subunits gene expression and proteasome activator PA28 $\alpha \beta$ gene and protein expressions display circadian rhythmicity in synchronized HEK 293 cells and HDF

Sub-confluent HEK 293 cells and HDF were synchronized using a serum shock as described in Materials and Methods. Cells were harvested after a $2 \mathrm{~h}$ exposure to a medium containing $50 \%(\mathrm{v} / \mathrm{v})$ of serum and then every $4 \mathrm{~h}$ for $50 \mathrm{~h}$ in a serum free medium. 
(A)(A') Total RNA was extracted and mRNA levels of the immunoproteasome catalytic subunits $\beta 1 i$ (open squares), $\beta 2 i$ (open circles) and $\beta 5 i$ (closed squares) were determined by Real Time qPCR. The gene expression of $\beta 5 i$ only exhibited a circadian rhythmicity in the two cellular models HEK 293 cells (A) and HDF (A') with a period of $22.6 \pm 1.3 \mathrm{~h}$ and $25.5 \pm$ $0.9 \mathrm{~h}$ respectively.

(B)(B') The expression of the immunoproteasome $\beta 1 \mathrm{i}$ (open squares), $\beta 2 \mathrm{i}$ (open circles) and $\beta 5 \mathrm{i}$ (closed squares) catalytic subunits was analyzed at the protein level in cellular extracts by using western blotting as described in Material and Methods. Quantification of proteasome subunit content was achieved using the ImageJ software. The protein expression of $\beta 5 \mathrm{i}$ only followed a circadian rhythmicity in the two cellular models HEK 293 cells (B) and HDF (B') with a period of $22.2 \pm 1.5 \mathrm{~h}$ and $23.2 \pm 0.5 \mathrm{~h}$ respectively.

$(\mathbf{C})\left(\mathbf{C}^{\prime}\right)$ Total RNA was extracted and mRNA levels PA28 activator isoforms $\alpha$ (open triangles) and $\beta$ (closed triangles) were determined by Real Time qPCR. The transcript expression of both $P A 28 \alpha$ and $P A 28 \beta$ isoforms is circadian with a period of $21.1 \pm 1.1 \mathrm{~h}$ and $21.7 \pm 1.4 \mathrm{~h}$ in HEK 293 cells $(\mathbf{C})$ and $26.2 \pm 0.8 \mathrm{~h}$ and $27.2 \pm 0.5 \mathrm{~h}$ in $\operatorname{HDF}\left(\mathbf{C}^{\prime}\right)$.

(D)(D') The expression of the PA28 activator isoforms $\alpha$ (open triangles) and $\beta$ (closed triangles) was analyzed at the protein level in cellular extracts by using Western blotting as described in Materials and Methods. Quantification of PA28 $\alpha$ and PA28 $\beta$ content was achieved using the ImageJ software. The protein expression of both PA28 $\alpha$ and PA28 $\beta$ isoforms exhibited a circadian rhythmicity with a period of $25.2 \pm 0.9 \mathrm{~h}$ and $21.8 \pm 1.3 \mathrm{~h}$, respectively in HEK 293 cells (D) and $25.6 \pm 1.2 \mathrm{~h}$ and $23.4 \pm 0.7 \mathrm{~h}$ in HDF (D').

Expression values of all genes were first normalized to the gapdh gene expression while expression values of all proteins were first normalized to the total protein load obtained upon Fast Green gel staining. A second normalization to the mean value of the time course experiment was performed for gene and protein expression levels.

Results are expressed as means $+/-\operatorname{SEM}, n=4$. All the curves and the periods were obtained using the Origin 9.1 software (OriginLab).

\section{Figure 3: Nrf2 expression, ROS level and oxidized glutathione display circadian rhythmicity in synchronized HEK 293 cells and HDF}

Sub-confluent HEK 293 cells and HDF were synchronized using a serum shock as described in Materials and Methods. Cells were harvested after a $2 \mathrm{~h}$ exposure to a medium containing $50 \%(\mathrm{v} / \mathrm{v})$ of serum and then every $4 \mathrm{~h}$ for $50 \mathrm{~h}$ in a serum free medium. 
(A)(A') Total RNA was extracted and mRNA levels of Nrf2 were determined by Real Time qPCR. The gene expression of Nrf2 exhibited a circadian rhythmicity with a period of $24.4 \pm$ $0.8 \mathrm{~h}$ for HEK 293 cells (A) and of $20.7 \pm 0.9 \mathrm{~h}$ for HDF (A').

(B)(B') The protein expression of Nrf2 was analyzed in cellular extracts by western blotting as described in Material and Methods. Quantification of Nrf2 protein content was achieved using the ImageJ software. The protein expression of Nrf2 exhibited a circadian rhythmicity with a period of $27.6 \pm 1.9 \mathrm{~h}$ for HEK 293 cells $(\mathbf{B})$ and of $23.1 \pm 1.2 \mathrm{~h}$ for HDF (B').

(C)(C') ROS levels were monitored by FACS analysis using the DCFDA fluorescent probe as described in Material and Methods. ROS levels followed a circadian rhythmicity in the two cellular models with a period of $22.6 \pm 0.8 \mathrm{~h}$ for HEK 293 cells $(\mathbf{C})$ and of $22.2 \pm 0.7 \mathrm{~h}$ for $\operatorname{HDF}\left(\mathbf{C}^{\prime}\right)$.

(D)(D') Oxidized (open squares) glutathione levels were determined using a GSH/GSSGGlo $^{\mathrm{TM}}$ Assay as described in Material and Methods. Oxidized (GSSG) glutathione levels exhibited circadian rhythmicity with a period of $24.6 \pm 0.36 \mathrm{~h}$ for HEK 293 cells (D) and of $22.1 \pm 2.5 \mathrm{~h}$ for $\operatorname{HDF}\left(\mathbf{D}^{\prime}\right)$.

Expression values of $N r f 2$ gene were first normalized to the gapdh gene expression while expression values of $\mathrm{Nrf} 2$ protein were first normalized to the total protein load obtained upon Fast Green gel staining. A second normalization to the mean value of the time course experiment was performed for gene and protein expression levels, ROS and oxidized and total glutathione levels.

Results are expressed as means $+/$ - SEM, $n=5$ for Nrf2 gene and protein expression, $n=3$ for ROS and oxidized and total glutathione levels. All the curves and the periods were obtained using the Origin 9.1 software (OriginLab).

Figure 4: Resistance of synchronized HEK 293 cells to t-BHP oxidative agent varies according to the timing of the stress.

Sub-confluent HEK 293 cells were synchronized with a serum shock treatment $\left(\mathrm{t}_{0 \mathrm{~h}}\right)$ and then at $\mathrm{t}_{2 \mathrm{~h}}, \mathrm{t}_{6 \mathrm{~h}}, \mathrm{t}_{18 \mathrm{~h}}, \mathrm{t}_{30 \mathrm{~h}}$ or $\mathrm{t}_{42 \mathrm{~h}}$ cells were exposed to an oxidative stress using $200 \mu \mathrm{M}$ of t-BHP for $1 \mathrm{~h}$. Cell viability was then measured using a XTT viability test and normalized to the value obtained $t_{0 h}$. Values represent the mean $+/-$ SEM of three independent experiments. Asterisks indicate statistical difference according to the ANOVA test $(* \mathrm{P}<0.01)$. 
Figure 5: Senescent fibroblasts synchronized by a serum shock no longer exhibit circadian rhythmicity for proteasome activities, ROS production and oxidized protein and glutathione levels

Sub-confluent senescent HDF were synchronized using a serum shock as described in Materials and Methods. Cells were harvested after a $2 \mathrm{~h}$ exposure to a medium containing $50 \%(\mathrm{v} / \mathrm{v})$ of serum and then every $4 \mathrm{~h}$ for $50 \mathrm{~h}$ in a serum free medium.

(A) Total RNA was extracted and mRNA levels of clock circadian genes were determined by Real Time qPCR. The expression of both per2 (closed squares) and bmall (open squares) exhibited a periodicity of $31.4 \pm 3.9 \mathrm{~h}$ and $32.9 \pm 4.7 \mathrm{~h}$ respectively.

(B) Intracellular proteasome peptidase activities were monitored using a Cell-Based Proteasome-Glo $\beta 5$ Assay as described in Materials and Methods. ChT-L (closed squares) activities were measured using the chemiluminescent substrate Suc-LLVY-Glo.

(C) Oxidized protein content (closed circles) was monitored using protein carbonyl western blot detection as described in Materials and Methods. Quantification of protein carbonyl content was achieved using the ImageJ software.

(D) The protein expression of Nrf2 was analyzed in cellular extracts by western blotting as described in Materials and Methods. Quantification of Nrf2 protein content was achieved using the ImageJ software.

(E) ROS levels were monitored by FACS analysis using the DCFDA fluorescent probe as described in Materials and Methods.

(F) Oxidized (open squares) glutathione levels were determined using a GSH/GSSG-Glo ${ }^{\mathrm{TM}}$ Assay as described in Materials and Methods.

Expression values of all genes were first normalized to the gapdh gene expression while expression values of all proteins were first normalized to the total protein load obtained upon Fast Green gel staining. A second normalization to the mean value of the time course experiment was performed for gene expression levels, carbonylated protein content and proteasome activities.

Results are expressed as means $+/-\operatorname{SEM}, n=5$. All the curves and the periods were obtained using the Origin 9.1 software (OriginLab).

\section{Figure 6: Model for the circadian regulation of proteasome activity}

A circadian expression of Nrf2 was found in both synchronized cellular models while ROS levels, that have been implicated in the Nrf2 inhibitor Keap1 oxidation and further dissociation and activation of $\mathrm{Nrf} 2$, were also shown to exhibit circadian rhythmicity. 
Oxidative stress dependent Nrf2-activation has been previously associated with an increase in the cellular capacity to degrade oxidized proteins that is attributable to the Nrf2-dependent increased expression of the $20 \mathrm{~S}$ proteasome subunits and its activator PA28 $\alpha \beta$ that contain an ARE motif in their promoter sequence. Hence, the oscillating expression and activation of Nrf2 is inducing a rhythmic transcriptional synthesis of its target genes, especially the proteasome catalytic subunits $\beta 1, \beta 2$ and $\beta 5$ and immunoproteasome $\beta 5 i$ as well as the proteasome activator PA28 $\alpha \beta$ subunits. The cyclic protein expression of the PA28 $\alpha \beta$ proteins unlike $\beta 1, \beta 2, \beta 5$ argues for PA28 $\alpha \beta$ being the main circadian mediated regulator of the rhythmic proteasome activity and rhythmic variation intracellular protein carbonyl levels.

List of figures:

Figure 1 
A

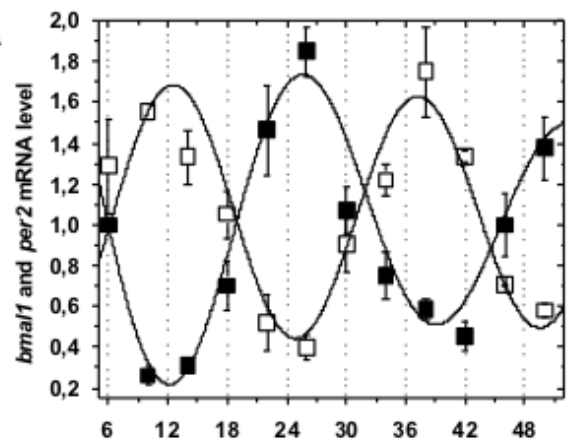

B

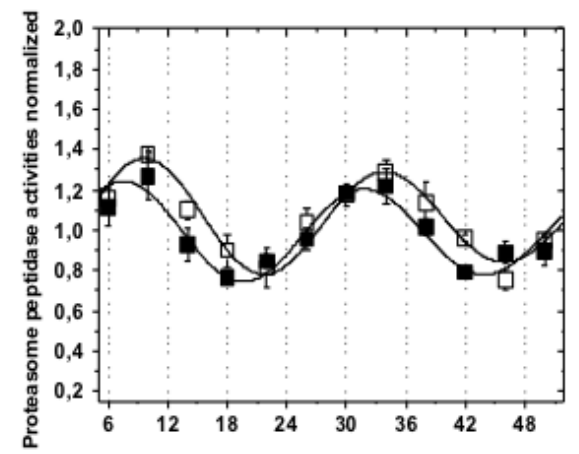

C

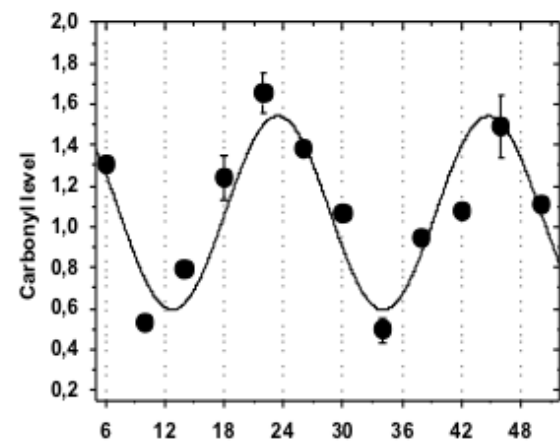

D

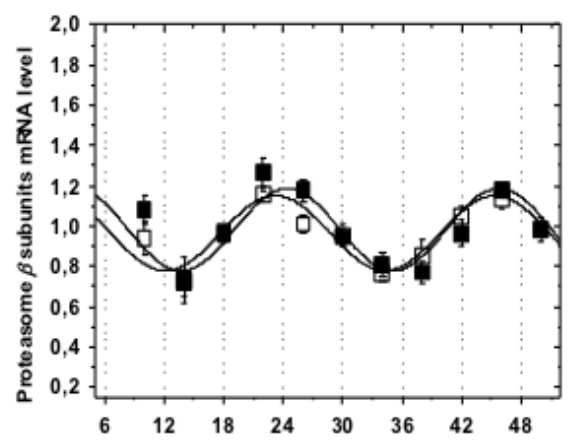

E

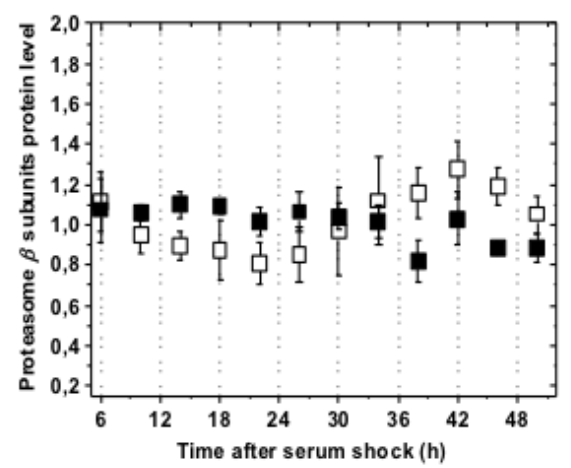

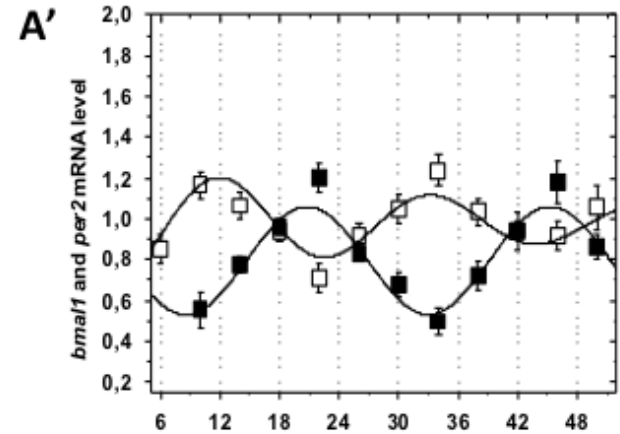

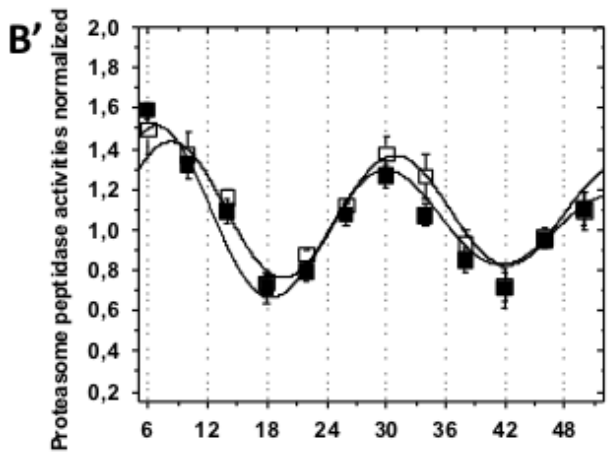

$\mathbf{C}^{\prime}$
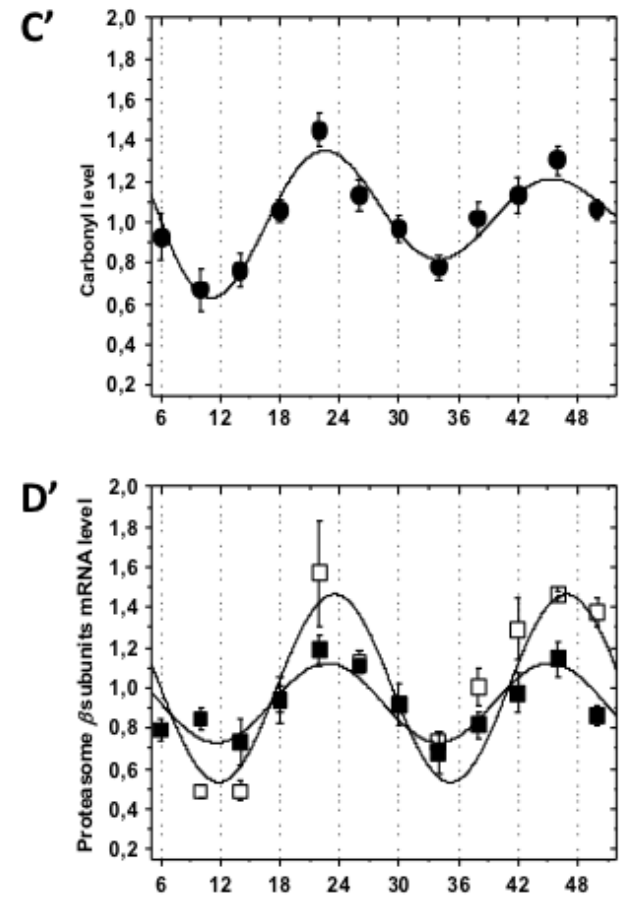

$\mathbf{E}^{\prime}$

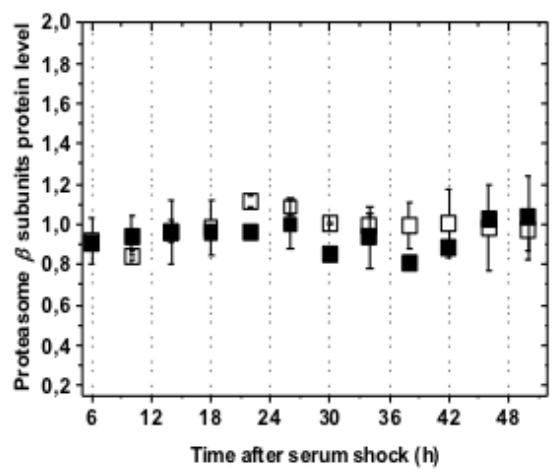


Figure 2 
A

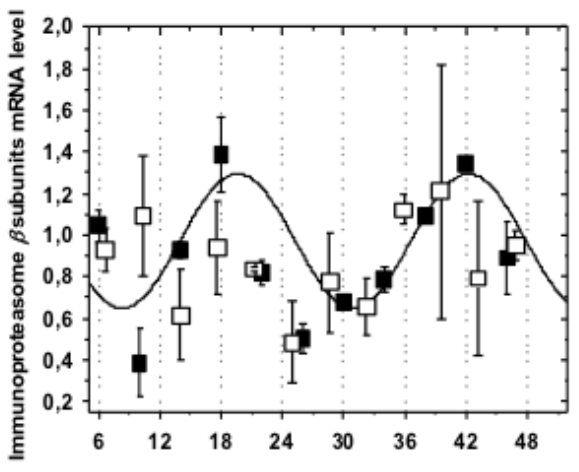

B

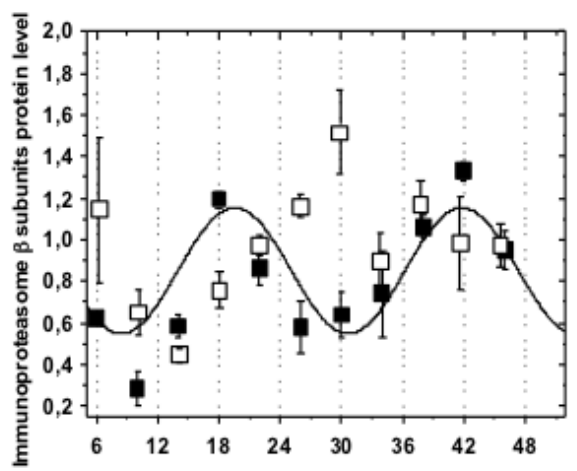

C

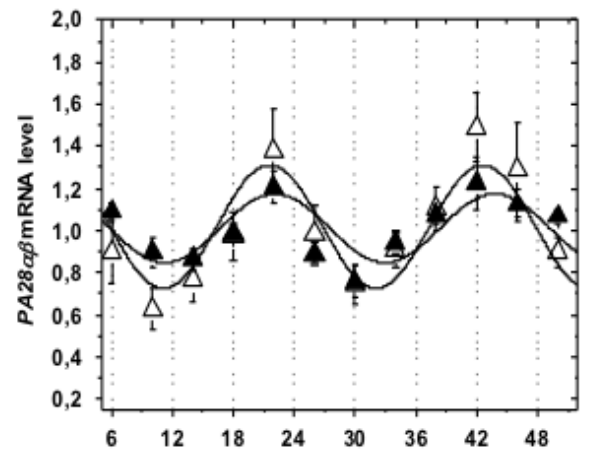

D

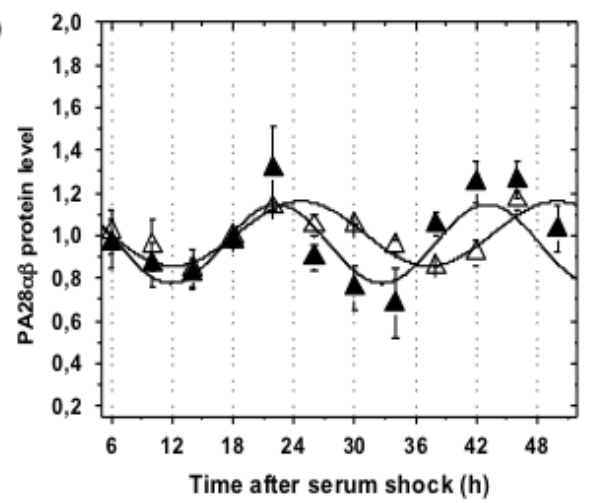

$A^{\prime}$

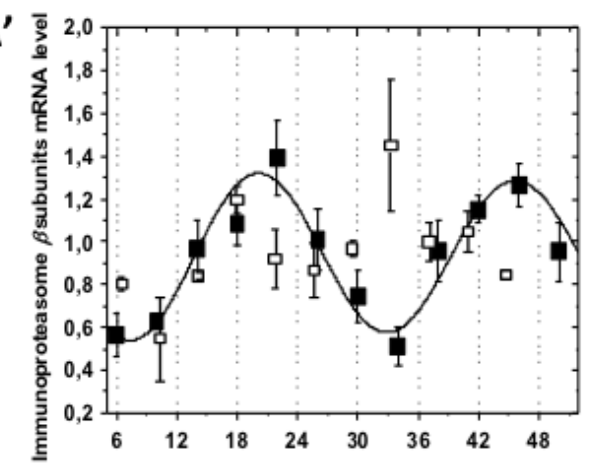

$B^{\prime}$

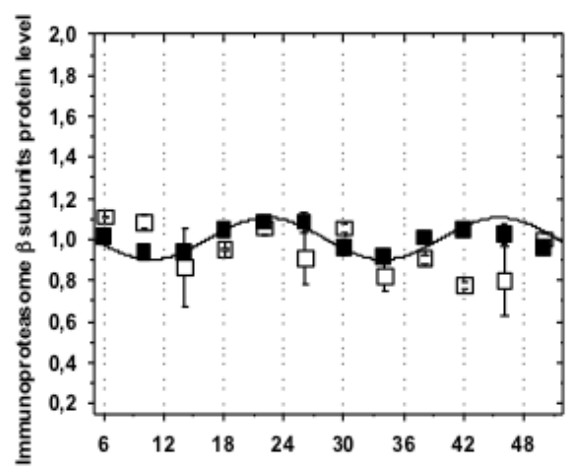

$C^{\prime}$

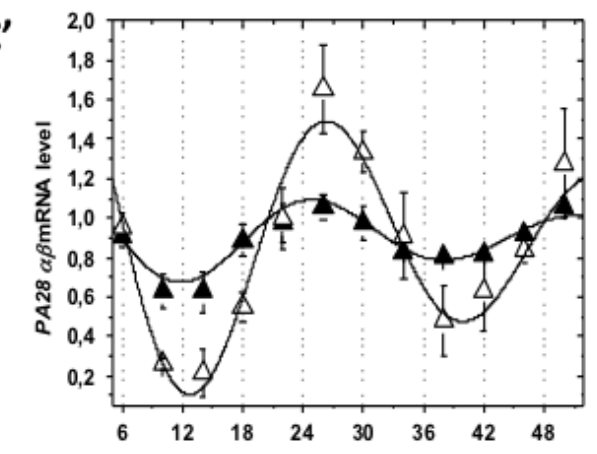

D'

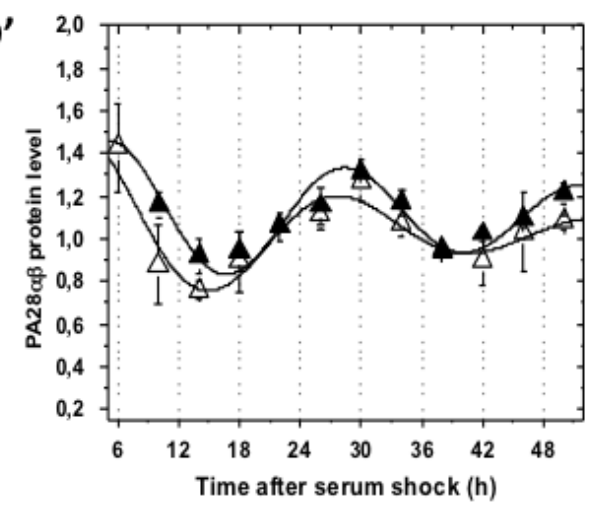


Figure 3 
A

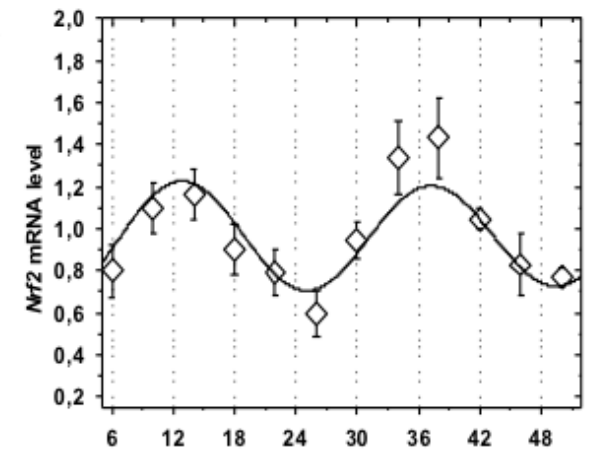

B

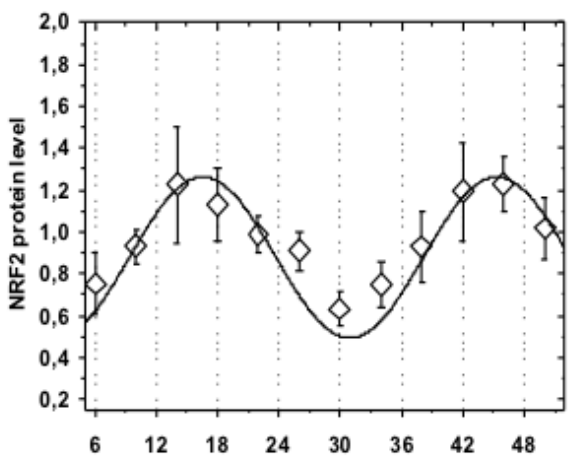

C

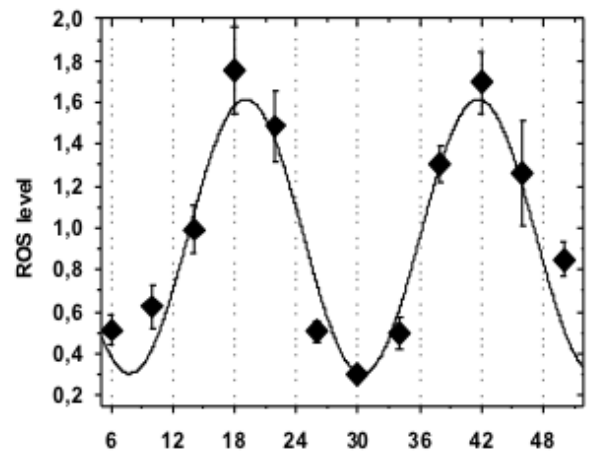

D

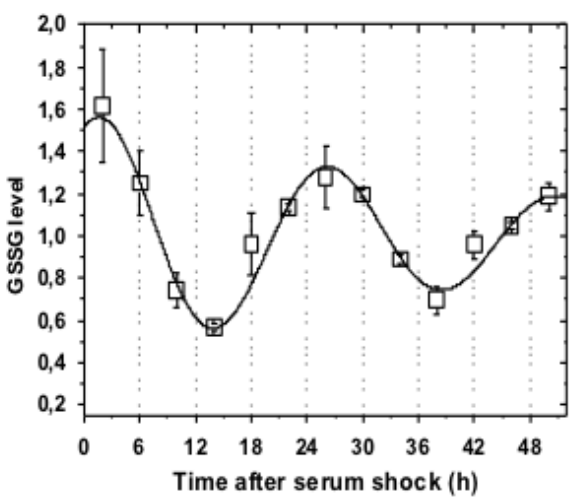

$A^{\prime}$

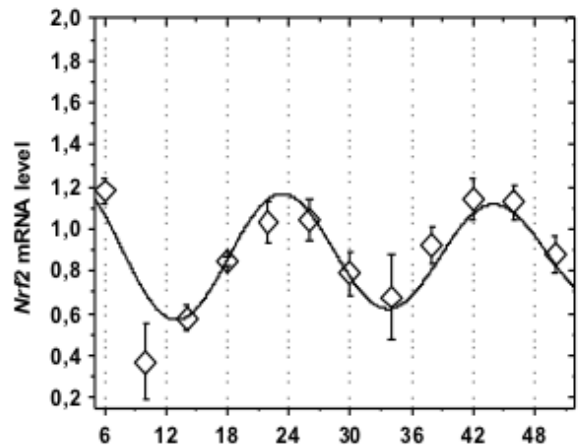

B'

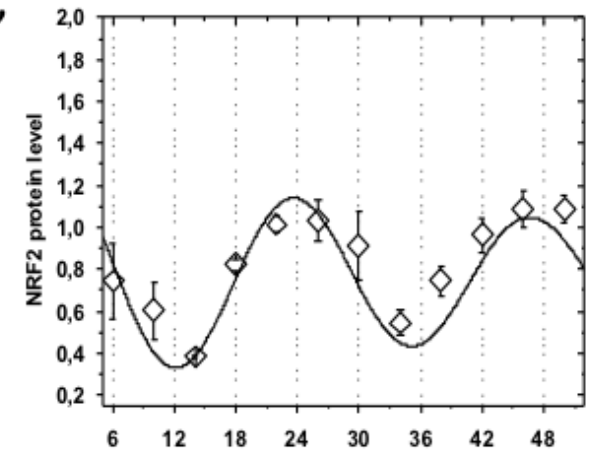

$C^{\prime}$

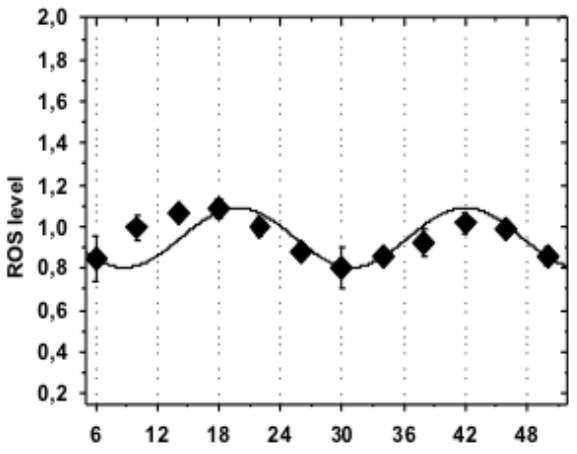

D'

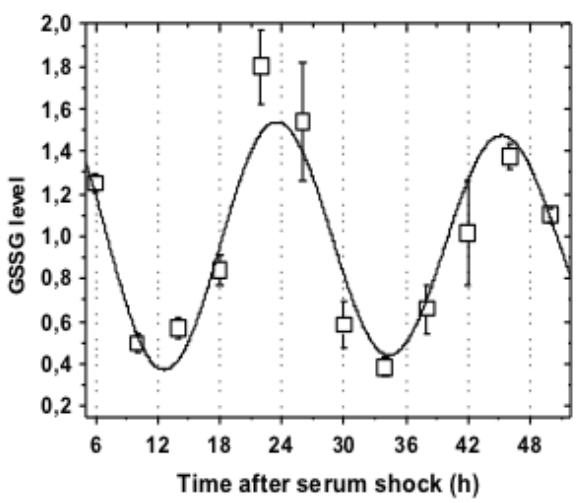


Figure 4 


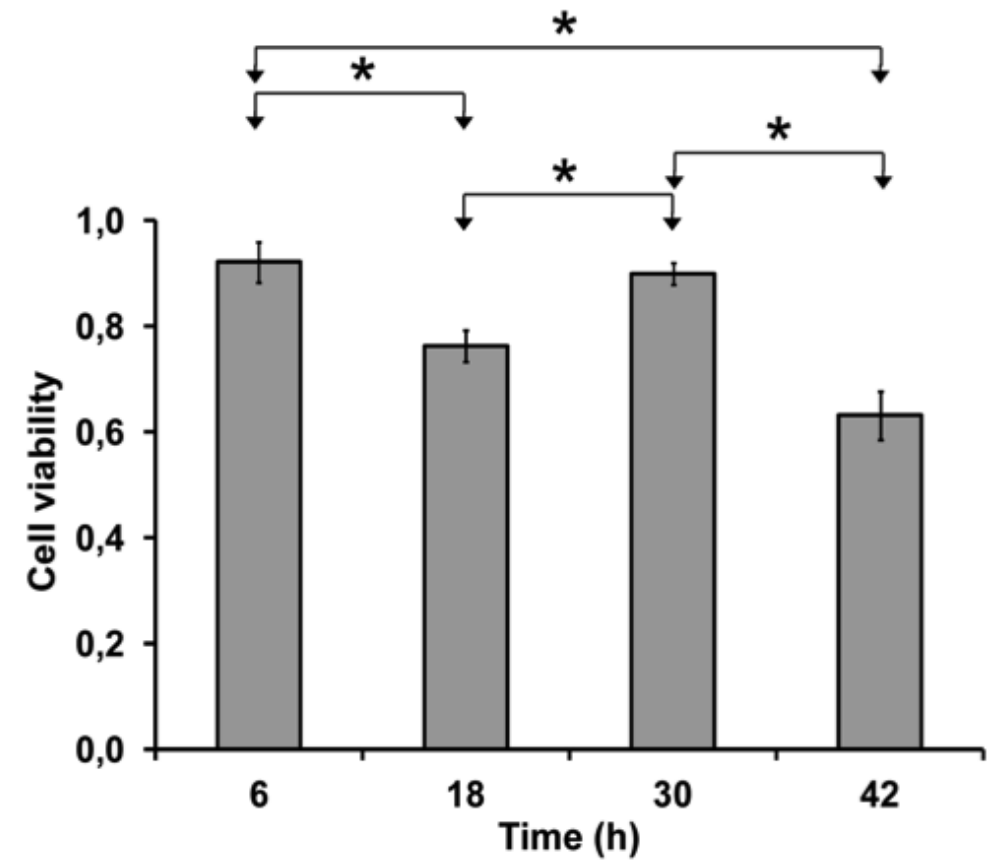


Figure 5 
A

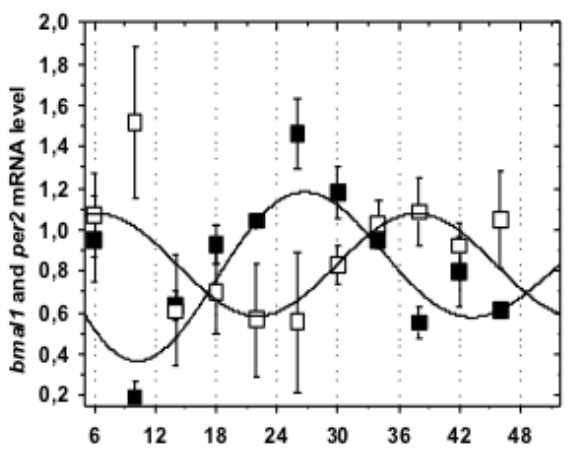

C

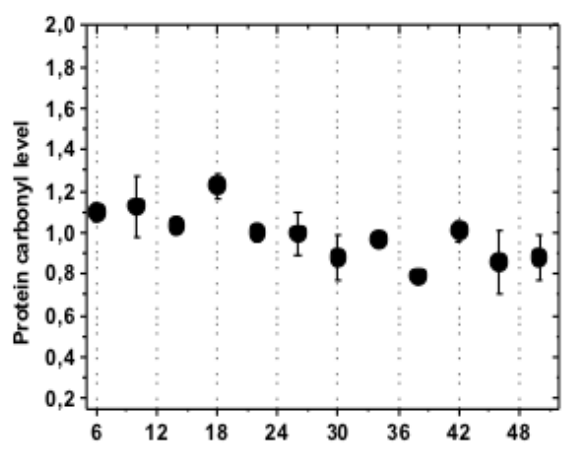

E

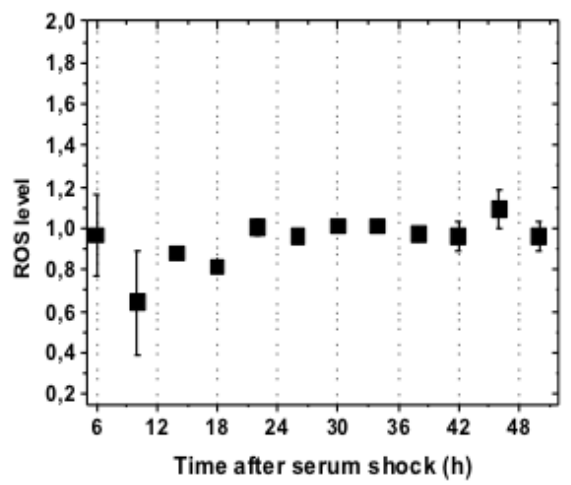

B

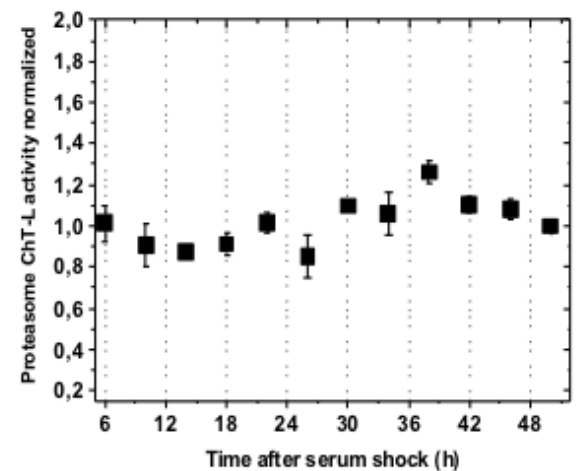

D

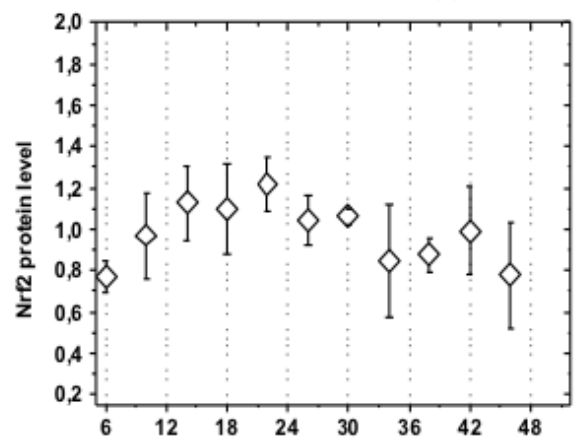

$\mathbf{F}$

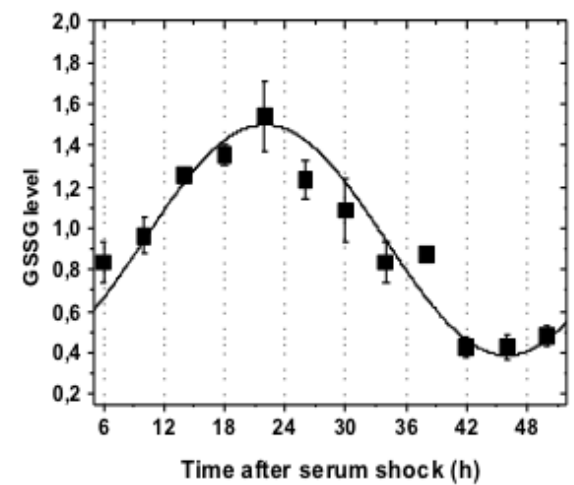


Figure 6 


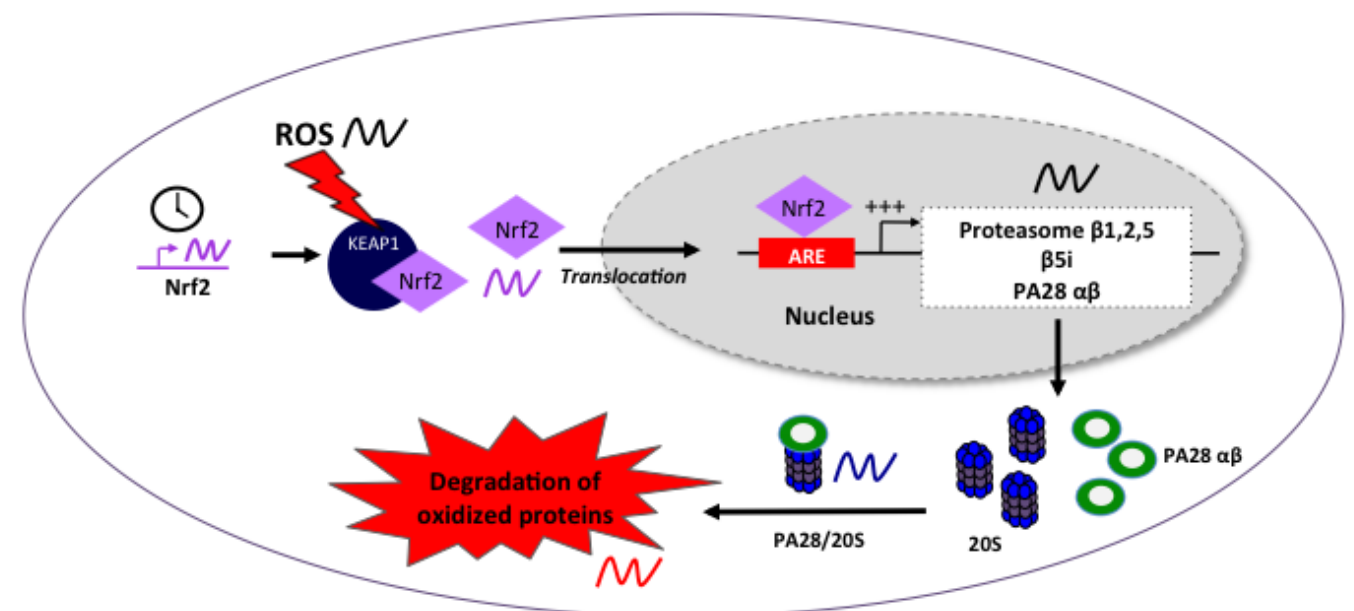


Graphical abstract:

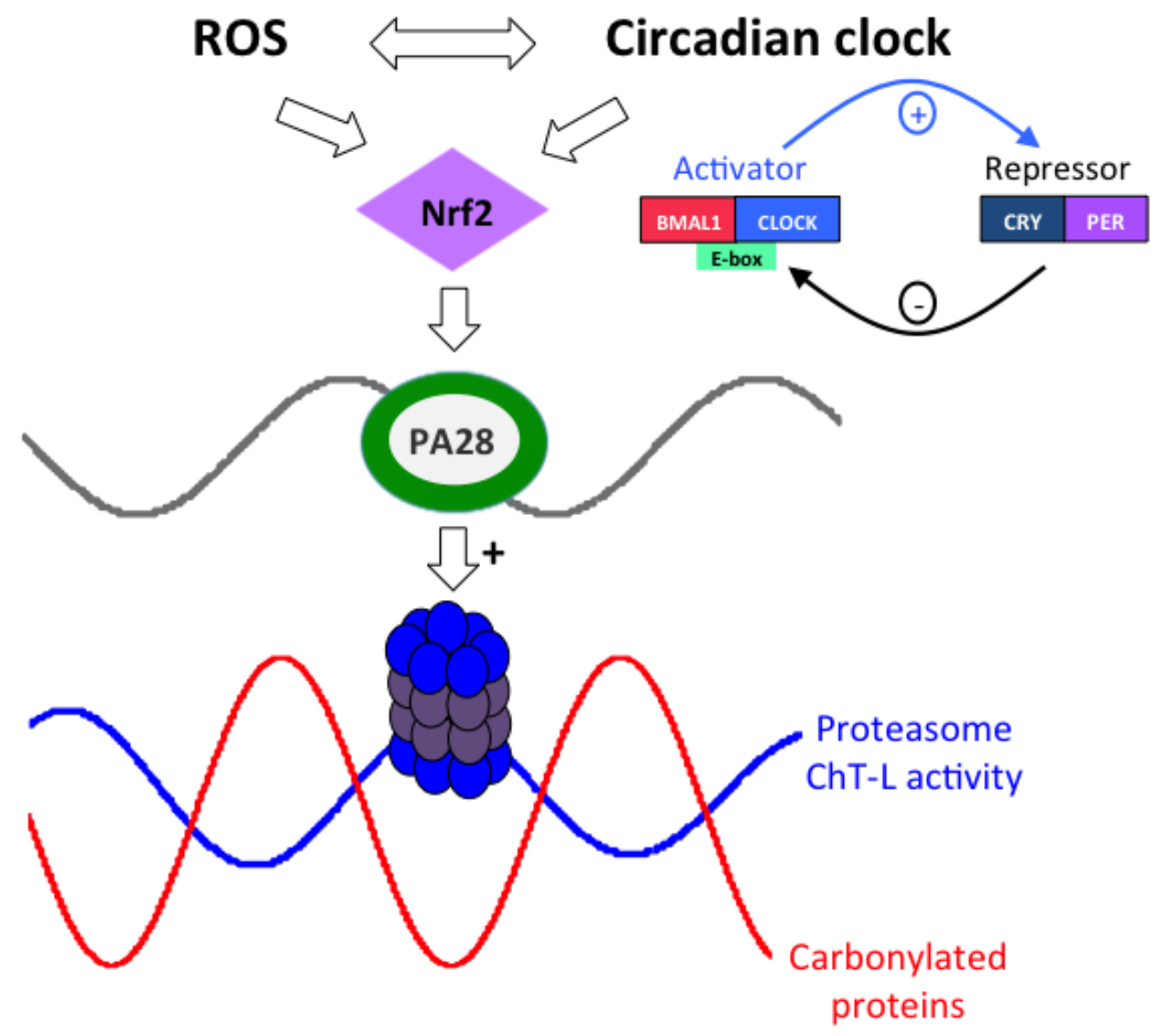

\section{Highlights}

- Proteasome activity and carbonylated protein levels exhibit circadian rhythmicity

- PA28 and NRF2 gene and protein expression also exhibit a circadian modulation

- PA28 and NRF2 circadian expression can thus explain the proteasome rhythmic activity

- HEK 293 cells show differential sensitivity to oxidative stress depending on timing

- Proteasome activity no longer exhibit circadian rhythmicity in senescent fibroblasts 